\title{
Lymphocyte-mediated neuroprotection in in vitro models of excitotoxicity involves astrocytic activation and the inhibition of MAP kinase signalling pathways.
}

Rajeev Shrestha $^{\mathrm{a}}$, Owain Millington ${ }^{\mathrm{a}}$, James Brewer ${ }^{\mathrm{b}}$, Kumlesh K Dev ${ }^{\mathrm{c}}$, Trevor J Bushell ${ }^{\mathrm{a}}{ }^{\mathrm{1}}$

${ }^{\mathrm{a}}$ Strathclyde Institute of Pharmacy and Biomedical Sciences, University of Strathclyde, 161

Cathedral Street, Glasgow, G4 ORE, UK

${ }^{b}$ Institute of Infection, Immunity and Inflammation, College of Medicine, Veterinary and Life

Sciences, University of Glasgow, Glasgow, G12 8QQ, UK

${ }^{c}$ Molecular Neuropharmacology, Department of Physiology, Trinity College, Dublin 2,

Ireland.

${ }^{1}$ Corresponding author: Dr Trevor J Bushell, Strathclyde Institute of Pharmacy and Biomedical Sciences, University of Strathclyde, 161 Cathedral Street, Glasgow, G4 0RE, UK. Email: trevor.bushell@ strath.ac.uk, Telephone: 44-141-548-2856, Fax: 44-141-5522562. 
Abbreviations: APCs, antigen presenting cells; BBB, blood-brain barrier; CM, conditioned media; CNS, Central nervous system, ERK, extracellular signal-regulated kinases; FAc, fluoroacetate; GFP, green fluorescent protein; KA, kainate; LCM, lymphocyte conditioned media; MAPK, mitogen activated protein kinases; MHC, major histocompatibility complex; OSCs, organotypic hippocampal slice cultures; OGD, oxygen-glucose deprivation; 


\begin{abstract}
It is well established that immunosurveillance is active in the CNS and plays a key role in several CNS disorders but the exact role of immune cells remains elusive. Thus, in the present study we investigated whether lymphocytes are protective / detrimental in in vitro models of excitotoxicty. Kainate (KA)-induced neuronal death was significantly reduced following exposure to mixed lymphocytes or purified $\mathrm{T}$ lymphocytes containing either activated or non-activated T-lymphocytes. Conditioned media from lymphocyte preparations, but not boiled conditioned media, was protective against KA-induced toxicity indicating soluble mediators underlie the observed neuroprotection with cytokine arrays indicating IL-16 as the likely candidate. A role for astrocytes was established as the neuroprotection was abolished in the presence of the glial toxin, fluoroacetate. Furthermore, lymphocytes inhibited p38 MAPK and ERK signalling pathways with pharmacological inhibition of these pathways mimicking the protective effect of lymphocytes. Similarly, lymphocytes were neuroprotective against oxygen-glucose deprivation (OGD)-induced cell death with the inhibition of p38 MAPK and ERK signalling pathways involved. These data indicate that lymphocytes are neuroprotective under our experimental conditions and we suggest that astrocytic activation and inhibition of MAPK signalling cascades are involved but further studies are required to investigate whether similar mechanisms underlie the actions of lymphocytes in in vivo experimental models of disease.
\end{abstract}

Keywords: astrocytes, lymphocytes, MAP kinases, neuroinflammation, neuroprotection, T cells. 


\section{Introduction}

Within the brain, there is an absence of lymphatic vessels and the classical major histocompatibility complex (MHC) molecules, leading to the suggestion that the brain shows limited immune surveillance or is an immunologically privileged area (Becher et al., 2006; Engelhardt, 2006). However, it is evident that the brain is not 'immune-privileged' as it is now well established that immune cells can cross the blood-brain barrier (BBB) (Hickey, 1999, Becher et al., 2006) and extensive studies have suggested that immune cells can play both detrimental or protective roles in central nervous system (CNS) function (for reviews see Cohen and Schwartz, 1999; Schwartz, 2005; Dittel, 2008).

It has been proposed that activated $\mathrm{T}$ cells cross the BBB irrespective of antigen specificity and, following recognition of specific antigens by antigen presenting cells (APCs) including astrocytes, dendritic cells and microglia, remain in the CNS to initiate an inflammatory reaction (Hickey et al., 1991; Liblau et al., 2013). Within the CNS, T cells have the capacity to proliferate, interact with resident APCs and produce cytokines that exacerbate the inflammatory response, which may contribute to the neurological symptoms observed in certain CNS diseases including amyotrophic lateral sclerosis and multiple sclerosis (Ponomarev et al., 2004, 2007; Batoulis et al., 2011). Indeed, aseptic cerebral injury is reduced in $\mathrm{T}$ cell-deficient recombinase activating gene knock out (RAG -/-) mice whereas cerebral injury is exacerbated when activated $\mathrm{CD} 4^{+} \mathrm{T}$ cells are re-introduced into these mice (Fee et al., 2003). In contrast to the general concept that $\mathrm{T}$ cell infiltration is detrimental to the CNS, T cells and B cells can also contribute to the maintenance of normal physiology (Cohen and Schwartz, 1999; Kipnis et al., 2004; Ziv et al., 2006; Wolf et al., 2009) and there is increasing evidence that $\mathrm{T}$ cells may be beneficial following CNS trauma (Cohen and Schwartz, 1999; Schwartz, 2005). An example of this is the impaired survival of facial motor 
neurons in severe combined immunodeficient (SCID) mice after experimental facial nerve axotomy, which is restored following transfer of wild-type splenocytes (a mixture of $\mathrm{T}$ and $\mathrm{B}$ cells) (Serpe et al., 1999). Moreover, adoptive transfer of T cells reactive to Cop-1 following injury also increases the number of surviving neurons (Kipnis et al., 2000). The underlying mechanism(s) by which lymphocytes rescue neurons is not clear but it is proposed that $\mathrm{T}$ cells are capable of producing neurotrophic factors (Moalem et al., 2000) and inducing glutamate clearance by astrocytes (Garg et al., 2008) and microglia (Shaked et al., 2005) which may contribute to their neuroprotective role.

Whether lymphocytes are detrimental or protective to the CNS may depend on the pathological conditions under which these cells infiltrate the CNS. In the present study, we have utilised organotypic slice cultures (OSCs) to investigate how lymphocytes modulate cell death induced by either exposure to kainate (KA) or oxygen glucose deprivation (OGD). OSCs were utilised in the current study as they are used extensively as a model for investigating neurodegenerative diseases and to study mechanisms involved in neuroprotection (Wang et al., 2005; Cho et al., 2007) and importantly for the current study, OSCs maintain their inflammatory responses under our culture conditions (Huuskonen et al., 2005). We show that cell death induced by both toxic insults is reduced in the presence of lymphocytes and this protection is independent of the $\mathrm{T}$ cell activation state. Furthermore, we demonstrate that this neuroprotection involves astrocytic activation via soluble mediators, with IL-16 being the lead candidate, and the inhibition of p38 mitogen activated protein kinase (MAPK) and extracellular signal-regulated kinases (ERK) signalling pathways. These data indicate that under the current experimental conditions, lymphocytes are neuroprotective and suggest therapeutic opportunities which may prove useful in future interventions in pathological CNS conditions. 


\section{Materials and Methods}

\subsection{Materials}

(2S,3S,4S)-3- (carboxymethyl)-4-(prop-1-en-2-yl)pyrrolidine-2-carboxylic acid (Kainic acid, KA), 2,3-dioxo-6-nitro-1,2,3,4-tetrahydrobenzo[f]quinoxaline-7- sulfonamide (NBQX), DL(-)-2-amino-5-phosphonopentanoic acid (DL-AP5), 4-[4-(4-Fluorophenyl)-2-[4(methylsulfinyl)phenyl]-1H-imidazol-5-yl] pyridine hydrochloride (SB203580), 1,4Diamino-2,3-dicyano-1,4-bis(2-aminophenylthio)butadiene (U0126) and 2-(4-Morpholinyl)8-phenyl-1(4H)-benzopyran-4-one (LY 294002) were obtained from Ascent Scientific, Bristol, UK. Sodium fluoroacetate (FA) was obtained from Sigma-Aldrich, Poole, UK. Antiphospho-p38 MAPK and anti-phospho-c-Jun N-terminal kinase (JNK) antibodies were obtained from Invitrogen, Paisley, UK. Anti-phospho-ERK, total anti-p38 MAPK, total antiJNK and total anti-ERK antibodies were obtained from Santa Cruz Biotechnology, Heidelberg, Germany. All horseradish peroxidase (HRP)-conjugated secondary antibodies were purchased from Jackson Immuno- Research Laboratories, Newmarket, UK. Alexa Fluor anti-rabbit 488 and Alexa Fluor 555 anti-mouse, were obtained from Invitrogen (Paisley, UK). Anti-microtubule associated protein 2 (MAP2) was obtained from Sigma-Aldrich (Poole, UK) with anti-green fluorescent protein (GFP) obtained from Clontech (Mountain View, USA).

\subsection{Preparation of organotypic hippocampal slice cultures.}

Organotypic hippocampal slice cultures (OSCs) were prepared as described previously (Greenwood and Bushell, 2010). Briefly, C57BL/6 mice (P4-7) were killed by cervical dislocation, according to Home Office UK Schedule 1 guidelines, followed by decapitation into ice-cold $70 \%$ ethanol. The brain was removed, transferred to ice-cold preparation media (50\% MEM, 25\% Hank balanced salt solution, 25\% horse serum, $25 \mathrm{mM}$ D-glucose and 1 
mM L-glutamine), bisected and glued to a sterile dissecting platform. Following submersion in ice-cold preparation media, parasaggital sections $(300 \mu \mathrm{m})$ were cut using a vibratome (Vibratome, Bannockburn, IL, USA) and the hippocampus removed. The slices were transferred to Millicel insert membranes $(0.5 \mu \mathrm{m}$; Millipore Corporation, Bedford, MA, USA) and placed into 6-well culture plates containing pre-equilibrated preparation media (1 $\mathrm{mL} /$ well). These were incubated at $37^{\circ} \mathrm{C} / 5 \% \mathrm{CO}_{2}$ for 24 hours after which the preparation media was replaced with serum-free culture media (SF media; 98\% Neurobasal-A; 2\% B27 supplement and $2 \mathrm{mM} \mathrm{L-glutamine)} \mathrm{and} \mathrm{maintained} \mathrm{at} 37^{\circ} \mathrm{C} / 5 \% \mathrm{CO}_{2}$. The culture media was then exchanged three times per week with all experiments performed on OSCs maintained for 13-15 days in vitro (DIV).

\subsection{Lymphocyte preparation.}

Peripheral lymph nodes were harvested from C57BL/6 mice (6-10 weeks old) and transferred to complete RPMI 1640 (cRPMI) media containing 10\% foetal calf serum and 2mM LGlutamine. The lymph nodes were homogenised and passed through a cell strainer $(40 \mu \mathrm{m}$ pore), transferred to a sterile tube and centrifuged at $400 \mathrm{x} g$ for 5 minutes. The pellet was then washed at least 2 times in serum free (SF) media and the cells re-suspended in SF media at $1 \times 10^{6}$ cells per $\mathrm{ml}$, the final concentration used in all experiments. T cells were purified from mixed lymphocyte preparations using magnetic cell sorting (pan T cell isolation kit; Miltenyi Biotec, UK) following the manufacturer's instructions. For lymphocyte preparations containing GFP-expressing $\mathrm{T}$ cells used to investigate cell-cell interactions, these were isolated from hCD2-GFP transgenic mice (Fumagalli et al., 2011). In experiments where $\mathrm{T}$ cell activation was required, non-purified lymphocyte preparations were stimulated with anti-mouse $\mathrm{CD} 3 \mathrm{e}(1 \mu \mathrm{g} / \mathrm{ml})$ for 24 hours whereas purified $\mathrm{T}$ cell preparations were exposed to both anti-mouse CD3e $(2 \mu \mathrm{g} / \mathrm{ml})$ and anti-mouse CD28 $(3 \mu \mathrm{g} / \mathrm{ml})$ for 24 hours. 


\subsection{Assessment of neuronal death using propidium iodide staining.}

OSCs (13-15 DIV) were checked under bright field microscopy for well-defined morphology prior to experimental use.. All drugs and lymphocytes $\left(1 \mathrm{X} 10^{6}\right.$ cells $\left.\mathrm{mL}^{-1}\right)$ were mixed in fresh culture media and equilibrated at $37^{\circ} \mathrm{C} / 5 \% \mathrm{CO}_{2}$. Conditioned media was prepared by centrifuging (2000 rpm, 10 minutes) media containing lymphocytes which were incubated for 18 hours at $37^{\circ} \mathrm{C} / 5 \% \mathrm{CO}_{2}$ and where appropriate, drugs were added directly to conditioned media. For assessment of neuronal death, OSCs were transferred to culture media containing propidium iodide (PI; $2 \mu \mathrm{M}$ ) following exposure to KA for 1 hour and incubated for 18 hours at $37^{\circ} \mathrm{C} / 5 \% \mathrm{CO}_{2}$. For oxygen glucose deprivation experiments, artificial cerebro-spinal fluid (aCSF) containing (in mM): $124 \mathrm{NaCl}, 3 \mathrm{KCl}, 26 \mathrm{NaHCO}_{3}, 2.5 \mathrm{NaH}_{2} \mathrm{PO}_{4}, 2 \mathrm{MgSO}_{4}, 2 \mathrm{CaCl}_{2}$ and 10 sucrose was continuously bubbled with nitrogen for at least for 2 hours prior to OSCs being transferred to OGD-aCSF and incubated in a nitrogen chamber for 30 minutes with the OSCs then transferred into fresh PI containing media and incubated for 18 hours at $37^{\circ} \mathrm{C} / 5 \%$ $\mathrm{CO}_{2}$. Where OSCs were incubated either with lymphocytes or conditioned media in the absence or presence of drugs, PI was added directly to the media and slices incubated for 18 hours at $37^{\circ} \mathrm{C} / 5 \% \mathrm{CO}_{2}$. Following treatment, OSCs were transferred to a microscopemounted incubator chamber $\left(37^{\circ} \mathrm{C}\right.$; Solent Scientific, Segensworth, UK) and PI fluorescent images were captured using a Nikon TE300 (Nikon, Kingston upon Thames, UK) inverted epi-fluorescent microscope (4X objective; Ex: 575/25 nm; Em: 626/28 nm) equipped with a Hamamatsu CCD camera (Hamamatsu Photonics, Welwyn Garden City, UK) controlled by Metamorph software (Molecular Devices Palo alto, CA, USA). The cell death was quantified by measuring the integrated density (mean fluorescence $\div$ slice area) of PI fluorescent images using ImageJ software (NIH) as described previously (Greenwood and Bushell, 2010). A concentration-response curve was generated using $\mathrm{KA}(3 \mu \mathrm{M}$ to $3 \mathrm{mM})$ to determine maximum neuronal death. As KA ( $3 \mathrm{mM}, 1$ hour) caused maximum neuronal death, all 
neuronal death values were expressed throughout in terms of this maximum value. In the OGD-induced cell death, a single treatment protocol was used.

\subsection{Cytokine array}

Commercially available cytokine antibody array dot blots (Proteome Profiler $^{\mathrm{TM}}$ Mouse Cytokine Array Panel A, R\&D Systems Europe) were used to measure the relative amounts of cytokines in fresh media, media incubated for $18 \mathrm{~h}$ and lymphocyte-conditioned media. A detection antibody, each targeted to a specific cytokine, was added to the treated media samples. The cytokine antibody array dot blots were then incubated overnight at $4^{\circ} \mathrm{C}$ with the media. Following this, the media was washed from the blot and a Streptavidin-HRP solution was added to the membrane for $30 \mathrm{~min}$ at room temperature. The cytokine array dot blot was again washed and a chemiluminescent HRP substrate (Millipore) was added to the membrane. The dot blots were then imaged using the FujiFilm LAS-3000 imaging system. Images were captured as 8 bit grayscale TIFFs and the relative pixel density of each spot on the array was quantified using Image J software.

\subsection{Western blotting}

Western blotting was performed as previously described (Greenwood and Bushell, 2010). Briefly following treatment, OSCs were transferred to ice-cold HEPES-buffered saline and kept on ice. OSCs were washed three times with ice-cold phosphate buffer solution (PBS, $2 \mathrm{ml}$ ) and then cut out from the insert membranes and transferred to solubilisation buffer and incubated on ice for at least 1 hour with occasional vortexing. Insert membranes were removed and OSCs were triturated with a syringe and needle. Total cellular protein concentration was estimated by Bradford reaction and samples were normalised to $0.444 \mu \mathrm{g} / \mu \mathrm{L}$ by adding solubilisation buffer. Samples were further diluted by $25 \%$ by adding 
sample buffer and boiled for 5 minutes to denature proteins. Samples were loaded in $10 \%$ SDS-polyacrylamide gels and subjected to electrophoresis which was blotted onto a nitrocellulose sheet. Non-specific binding was blocked by incubating blots with NaTT buffer containing $3 \%$ bovine serum albumin (BSA) for 2 hours. Blots were then incubated overnight with specific primary antibodies prepared in $0.2 \% \mathrm{BSA} / \mathrm{NaTT}$ then washed with NaTT buffer for 2 hours before incubating with either horse-radish peroxidase-conjugated anti-mouse or anti-rabbit IgG secondary antibody for 90 minutes. Blots were again washed for 2 hours and developed using enhanced chemiluminescence (ECL) reagents with a X-OMAT developing machine. After detection of phosphor-specific bands, blots were stripped using a stripping solution for 1 hour on an orbital shaker. Blots were then washed for 30 minutes with NaTT buffer. These blots were then re-blocked and re-probed with non-phospho-specific antibody as described above.

\subsection{Immunohistochemistry}

OSCs were incubated with lymphocyte preparations containing GFP-expressing $\mathrm{T}$ cells for 18 hours after treatment with or without KA for 1 hour. To confirm detection of GFPexpressing T cells, $1 \times 10^{6}$ lymphocytes were added on the top of slices as opposed to the usual arrangement of $\mathrm{T}$ cells underneath the transwell membrane. After 18 hours, the media was removed by suction and $1 \mathrm{ml}$ cold $4 \%$ paraformaldehyde (PFA) was added above and below the insert membrane for 5 minutes. OSCs were washed twice with cold PBS and 100\% methanol was then added above and below the membrane for 10 minutes. Following PBS washes, OSCs were incubated overnight with permeabilization solution $(0.5 \%$ Triton $\mathrm{X}-100$ in PBS) before blocking with 20\% Bovine serum albumin in PBS for 4 hours at room temperature. Anti-MAP2 (1:5000) and anti-GFP (1:400) antibodies were then applied in 5\%

BSA blocking solution to the OSCs overnight at $4^{0} \mathrm{C}$. OSCs were then washed with blocking 
solution and appropriate fluorescent secondary antibodies (Alexa488 and Alexa555) applied at room temperature (3 hours). OSCs were then washed with 5\% blocking solution and

mounted, using Vectashield, on a glass microscope slide. Z stack images were captured using a Leica TCS SP-5 laser scanning confocal system with a 40x oil immersion lens and optimised using Adobe Photoshop (version 7.0).

\subsection{Data analysis}

All data are presented as mean \pm S.E.M. with the number of slices indicated for all experiments performed on at least four different culture preparations. The differences between groups were analysed using a Student's unpaired $t$-test or one-way ANOVA with Tukey's post-hoc analysis as appropriate. In all analyses, $\mathrm{p}<0.05$ were considered as significant. 


\section{Results}

\subsection{Lymphocytes are not toxic to OSCs.}

As it is unclear whether lymphocytes play either a protective or pathogenic role in the CNS, we first sought to determine whether lymphocytes were neurotoxic to OSCs under our experimental conditions. Initially, OSCs were treated with a range of concentrations of KA (3 $\mu \mathrm{M}-3 \mathrm{mM}$ ) for 1 hour before staining with propidium iodide (PI) to determine the maximum cell death. As per previous studies in our laboratory (Greenwood and Bushell, 2010), KA induces neurotoxicity in a concentration-dependent manner with maximum cell death observed at 3mM (Figure 1A \& B). Hence in all further experiments, OSCs were treated with KA (300 $\mu \mathrm{M}, 60 \mathrm{~min})$ as a positive control of neurotoxicity with all levels of cell death being expressed as a percentage of this $3 \mathrm{mM}$ KA maximum. This toxicity was completely abolished in the presence of both the AMPA/KA antagonist, NBQX (20 $\mu \mathrm{M})$, and the NMDA antagonist, DL-AP5 $(100 \mu \mathrm{M} ; \mathrm{n} \geq 4 ; \mathrm{p}<0.001$ compared to KA (300 $\mu \mathrm{M})$ alone; Figure 1C). In contrast to the effects of KA, mixed lymphocyte preparations did not induce neurotoxicity in OSCs when exposed to lymphocytes for up to 18hours ( $\mathrm{P}>0.05$ compared to control, Figure 1A \& C). This lack of neurotoxicity was evident irrespective of $\mathrm{T}$ cell activation, since OSCs exposed to T cells in the presence $(18 \mathrm{~h}, \mathrm{n}=17)$ or absence $(18 \mathrm{~h}, \mathrm{n}=9)$ of anti-CD3e stimulation displayed no evidence of cell death (Figure 1C). Together, these data demonstrate that lymphocytes are not directly neurotoxic to OSC in our mixed cell culture system.

\subsection{Lymphocyte preparations exhibit neuroprotection against KA-induced cell death.}

Having established that lymphocyte preparations are not neurotoxic to OSCs, we investigated whether OSC exposure to lymphocytes modulates KA-induced excitotoxicity. The presence 
of lymphocytes for only 1 hour during initial treatment with $\mathrm{KA}(300 \mu \mathrm{M}, 1 \mathrm{~h})$ resulted in similar levels of OSC toxicity as KA alone and this was independent of T cell activation state (non-activated T cells, $\mathrm{n}=16, \mathrm{P}>0.05$ compare to KA alone; activated $\mathrm{T}$ cells, $\mathrm{n}=14, \mathrm{P}>0.05$ compare to KA alone, Figure 2B). In contrast, significant neuroprotection was observed when OSCs were co-cultured with lymphocytes for 18hours following an initial exposure to KA $(300 \mu \mathrm{M}, 1 \mathrm{~h})$. This lymphocyte-mediated neuroprotection was independent of $\mathrm{T}$ cell activation as KA-induced toxicity was reduced from $67.5 \pm 5.6 \%(\mathrm{n}=30)$ to $50.8 \pm 3.8 \%$ $(\mathrm{n}=48, \mathrm{P}<0.05$ compared to $300 \mu \mathrm{M}$ KA alone, Figure $2 \mathrm{~A} \& \mathrm{~B})$ and $45.4 \pm 3.4 \%(\mathrm{n}=50$, $\mathrm{P}<0.01$ compared to $300 \mu \mathrm{M} \mathrm{KA}$ alone, Figure $2 \mathrm{~A} \& \mathrm{~B})$ for preparations containing nonactivated and activated T cells respectively. Thus, in our model of KA-induced excitotoxicity, lymphocytes are able to exhibit neuroprotection and this is independent of $\mathrm{T}$ cell activation.

\subsection{Purified T cells exhibit neuroprotection against KA-induced cell death.}

Having determined that a mixed lymphocyte population is neuroprotective in our experimental system, we next sought to determine the cell type responsible for mediating protection. Using flow cytometry, we confirmed that approximately $70 \%$ of the cells in our lymphocyte preparations were $\mathrm{T}$ cells $(68.5 \pm 1.8 \%, \mathrm{n}=16)$. Therefore, to investigate the role of $\mathrm{T}$ cells in the observed protection against KA-induced neuronal death, $\mathrm{T}$ cells were purified from mixed lymphocyte preparations. In agreement with our initial findings, mixed lymphocyte preparations significantly reduced cell death in OSCs from $66.8 \pm 2.7 \%(n=10)$ to $31.6 \pm 3.1 \%$ ( $\mathrm{n}=8, \mathrm{P}<0.001$ compared to $300 \mu \mathrm{M}$ KA alone, Figure $2 \mathrm{C}$ ). Similarly, $\mathrm{T}$ cells purified from the same lymphocyte preparation significantly reduced KA-induced neuronal death, an effect that was independent of $\mathrm{T}$ cell activation state with cell death being reduced to $42.7 \pm 2.9 \%$ ( $\mathrm{n}=9, \mathrm{P}<0.001$ compared to $300 \mu \mathrm{M}$ KA alone, Figure $2 \mathrm{C})$ and $51.7 \pm 5.8 \%$ 
$(\mathrm{n}=6, \mathrm{P}<0.05$ compared to $300 \mu \mathrm{M}$ KA alone, Figure $2 \mathrm{C})$ for non-activated and activated purified $\mathrm{T}$ cells respectively.

\subsection{Soluble mediators underlie lymphocyte-induced neuroprotection.}

Having established that lymphocyte preparations and purified $\mathrm{T}$ cells are neuroprotective under our experimental conditions, we investigated the mechanisms underlying the observed neuroprotection. To determine whether soluble mediators underlie lymphocyte-mediated neuroprotection, lymphocyte conditioned media (LCM) was assessed for protection against KA-induced neurotoxicity. Lymphocytes were cultured for 18 hours alone or in the presence of OSCs and the purified conditioned media transferred to KA-treated OSCs. Cell death in OSCs maintained in LCM for 18 hours after initial exposure to KA was significantly reduced irrespective of whether LCM was purified from mixed cultures of lymphocytes and OSC or from lymphocytes alone, suggesting that soluble mediators are responsible for the neuroprotective effects and that these are solely produced by lymphocytes (Figure 3A \& B). In contrast, the neuroprotective effect of LCM was abolished when the media was boiled $(63.4 \pm 4.8 \%, \mathrm{n}=7, \mathrm{P}>0.05$ compared to $300 \mu \mathrm{M}$ KA alone, Figure $3 \mathrm{~A} \& \mathrm{~B})$, suggesting the neuroprotective factor in LCM is protein in nature. Furthermore, to confirm that lymphocytes were essential for the LCM-mediated neuroprotection, conditioned media (CM) taken from KA treated slices $(61.8 \pm 3.8 \%, \mathrm{n}=9, \mathrm{P}>0.05$ compared to $300 \mu \mathrm{M}$ KA alone $)$ and CM from primary hippocampal cultures $(61.1 \pm 3.6 \%, \mathrm{n}=10, \mathrm{P}>0.05$ compared to $300 \mu \mathrm{M}$ KA alone) were ineffective against KA-induced neurotoxicity. Further confirmation that direct cell-cell interaction is not required for the observed neuroprotection was achieved by utilising lymphocyte preparations containing GFP-expressing T cells isolated from hCD2GFP transgenic mice in order that any $\mathrm{T}$ cell infiltration of the OSCs could be easily visualised. Examination of slices, either with or without the exposure of KA, maintained for 
18 hours in the presence of lymphocyte preparations containing GFP-expressing T cells under conditions identical to those described above, revealed no infiltration of $\mathrm{T}$ cells into the OSCs although GFP-expressing T cells were observed when applied directly to the slice (data not shown). These data strongly suggest that soluble mediators released from lymphocytes are responsible for the observed neuroprotection, with no cell-cell interaction required. In order to try and identify the soluble mediator(s) involved, arrays were performed to analyse the levels of 40 cytokines found in fresh media, media incubated for 18 hours and LCM that was prepared as per the neuroprotective experiments described earlier. These cytokine arrays revealed that a robust increase in IL-16 levels were evident in LCM compared to fresh and incubated media (Figure 3C \& D) with the level of all other cytokines investigated being similar in all three media preparations indicating that IL-16 may be the soluble mediator underlying the neuroprotective effects observed in the current experiments.

\subsection{Lymphocyte mediated neuroprotection involves astrocytic activation and inhibition of ERK and p38 MAP kinase signalling.}

Despite having identified IL-16 as the potential cytokine underlying the lymphocytemediated neuroprotection, the cell type and signalling pathways within the OSCs on which it acts to produce this effect is unknown. Hence we next utilised the glial metabolic inhibitor, fluoroacetate (FAc), which we have successfully used to investigate astrocyte function in previous studies (Greenwood and Bushell, 2010; Gan et al., 2011). Exposure of OSCs to FAc $(10 \mu \mathrm{M}, 3 \mathrm{~h})$ did not affect KA-induced cell death $(\mathrm{n}=12, \mathrm{P}>0.05$ compared to $300 \mu \mathrm{M}$ KA alone, Figure 4A). However, neuroprotection elicited by $\operatorname{LCM}(50.7 \pm 5.2 \%, \mathrm{n}=15$, $\mathrm{P}<0.01$ compared to $300 \mu \mathrm{M}$ KA alone) was significantly reduced in FAc-treated OSCs $(66.2$ $\pm 2.8 \%, \mathrm{n}=10, \mathrm{P}<0.001$ compared to $300 \mu \mathrm{M} \mathrm{KA}+\mathrm{LCM}$, Figure 4A), suggesting that astrocytes are important in the neuroprotection induced by lymphocytes. We then examined 
whether common signalling pathways that are known to be modulated by numerous immunological mediators, namely MAPKs, are involved in the lymphocyte-mediated neuroprotection. Initial experiments were performed to determine if and how MAPK activity was modulated following KA-induced cell death in the absence and presence of lymphocytes. However, exposure of OSCs to KA led to considerable variability in the MAPK activity between slices and experiments and thus we decided to determine the effect on MAPK activity of subjecting untreated OSCs to lymphocytes. Exposure of OSCs to lymphocytes (18h) resulted in a significant reduction in ERK and p38 MAPK activity to $66.2 \pm 6.1 \%$ of control $(n=10, P<0.05$ compared to control, Figure 4B \& C) and $64.1 \pm 4.5 \%$ of control $(n=6$, $\mathrm{P}<0.05$ compared to control, Figure 4B \& C). In contrast, JNK 1/2 activity was unaffected by exposure to lymphocytes $(108.6 \pm 12.7 \%$ of control, $\mathrm{n}=10, \mathrm{P}>0.05$ compared to control, Figure 4B \& C). If this lymphocyte-mediated reduction in ERK and p38 MAPK activity in untreated slices contributed to the observed lymphocyte-mediated neuroprotection against KA-induced cell death, the pharmacological inhibition of both kinases should also be protective against KA-induced neurotoxicity. Indeed, co-incubation with the p38 MAPK inhibitor, SB203580 $(100 \mu \mathrm{M})$, and the upstream ERK inhibitor, U0126 $(20 \mu \mathrm{M})$ significantly reduced KA-induced cell death from $71.8 \pm 2.8(\mathrm{n}=15)$ to $53.1 \pm 1.1(\mathrm{n}=11, \mathrm{P}<0.001$ compared to $300 \mu \mathrm{M}$ KA, Figure 4D). Having shown a role for MAPK inhibition, we also investigated whether the PI3K pathway is involved in lymphocyte-mediated neuroprotection. To negate any issues regarding PI3K inhibition on lymphocyte function, pharmacological inhibition of PI3K using LY294002 $(10 \mu \mathrm{M})$ was performed in the presence of lymphocyte conditioned media (LCM). LCM significantly reduced KA-induced cell death from $71.8 \pm$ $2.8(n=15)$ to $53.3 \pm 2.0(n=11, P<0.01$ compared to $300 \mu M$ KA, Figure 4D) and this was unaffected by treatment with LY294002 $(56.6 \pm 2.2 \%, \mathrm{n}=13, \mathrm{P}>0.05$ compared to $300 \mu \mathrm{M}$ KA + LCM, Figure 4D). In the absence of LCM, no change in KA-induced toxicity was 
observed in the presence of LY294002 $(68.7 \pm 1.6 \%, \mathrm{n}=6, \mathrm{P}>0.05$ compared to KA alone, Figure 4D).

\subsection{Lymphocytes are protective against OGD-induced toxicity.}

Having established the neuroprotective effect of lymphocytes against KA-induced toxicity, we further investigated whether lymphocytes protect OSCs against another in vitro model of neurotoxicity, OGD. OGD (30 mins) induced significant cell death in OSCs and exposure to lymphocytes reduced the neurotoxicity to $61.6 \pm 3.0 \%$ of OGD control $(\mathrm{n}=19, \mathrm{P}<0.001$ compared to control, Figure 5A \& B). LCM also significantly reduced OGD-induced cell death to $65.9 \pm 7.4 \%$ of OGD control $(\mathrm{n}=5, \mathrm{P}<0.05$ compared to control, Figure $5 \mathrm{~B})$ indicating that in agreement with the KA-induced toxicity experiments, soluble mediators released by lymphocytes are responsible for the observed neuroprotection against OGD. However, in contrast to the KA experiments, pre-treatment of OSCs with FAc $(10 \mu \mathrm{M}, 3 \mathrm{hr})$ had no significant effect LCM-mediated neuroprotection $(56.8 \pm 6.0 \%$ of OGD control, $\mathrm{n}=6$, P>0.05 compared to LCM alone, Figure 5B), a finding which suggests that astrocytes do not

play a significant role in the protection against OGD. However, similar signalling mechanisms appear to underlie the observed neuroprotection as co-incubation with SB203580 $(100 \mu \mathrm{M})$, and U0126 $(20 \mu \mathrm{M})$ significantly reduced OGD-induced toxicity to 66.3 $\pm 5.9 \%$ of control ( $\mathrm{n}=9, \mathrm{P}<0.01$ compared to OGD control, Figure $5 \mathrm{~B}$ ) whereas LY294002 $(10 \mu \mathrm{M})$ was without effect $(72.5 \pm 1.6 \%$ of OGD control, $\mathrm{n}=6, \mathrm{P}>0.05$ compared to LCM alone, Figure 5B). 


\section{Discussion}

In the present study, we show that lymphocytes are protective in two in vitro models of neurotoxicity and that protection is independent of $\mathrm{T}$ cell activation. We suggest that the lymphocyte-mediated protection involves soluble mediators, presumably IL-16 and, at least in the case of KA-induced toxicity, is mediated indirectly via astrocytes. In addition, we propose that an inhibition of both p38 MAPK and ERK activity contributes to the observed neuroprotection.

\subsection{Lymphocytes are neuroprotective independent of $T$ cell activation state.}

The role of the immune system in modulating the CNS under physiological and pathophysiological conditions is an area of intense interest. Classically, activation of the immune system and recruitment of immune cells was thought to contribute to and exacerbate pathophysiological conditions within the CNS. Indeed, in the archetypal autoimmune CNS disease, multiple sclerosis, it is established that lymphocytes invade the CNS and contribute to the disease neuropathology (Larochelle et al., 2011; Stadelmann, 2011) and a role for neuroinflammation has been implicated in numerous CNS diseases including Alzheimer's disease (Grammas, 2011) and Parkinson's disease (Barnum and Tansey, 2010; Qian et al., 2010) . However, studies also suggest that lymphocytes may have a neuroprotective role in the CNS when investigated using models of spinal cord injury (Yoles et al., 2001; Sroga et al., 2003; Beck et al., 2010), facial nerve axotomy (Serpe et al., 1999; Sanders and Jones, 2006; Xin et al., 2011) and ischaemia (Frenkel et al., 2005; Liesz et al., 2009). This latter role for lymphocytes reflects our finding in the present study that lymphocytes are not neurotoxic to OSCs under our experimental conditions but are protective against KA-induced and OGD-induced toxicity. Our findings are in agreement with a previous study which focused specifically on the consequence of exposing organotypic cultures to $\mathrm{T}$ cell subtypes 
(Wolf et al., 2002). It revealed that both Th1 and Th2 cells were protective in a contact independent manner. However in contrast to our own study, increased neuroprotection was observed following $\mathrm{T}$ cell activation and protection was against secondary damage initiated by explantation of tissue from living animal to the culture dish. Conversely, our study utilised established models of neurodegeneration and experimental ischaemia to assess lymphocytemediated neuroprotection (Noraberg et al., 2005; Wang et al., 2005; Zheng et al., 2011). Hence we have shown for the first time that lymphocytes are protective in established in vitro models of neurodegeneration and ischaemia. Furthermore, in our hands, this neuroprotection is independent of the $\mathrm{T}$ cell activation state with lymphocyte-mediated neuroprotection being similar whether or not they contained activated $\mathrm{T}$ cells. This was also true when purified $\mathrm{T}$ cells were utilised, with both activated and non-activated purified $\mathrm{T}$ cells being protective against KA-induced neurotoxicity. The discrepancy in the role of $\mathrm{T}$ cell activation state between our studies could simply be due to the experimental parameters used to investigate $\mathrm{T}$ cell function, but further investigation into this is beyond the scope of this study.

As stated previously, the finding that $\mathrm{T}$ cells were neuroprotective is in agreement with previous studies where $\mathrm{T}$ cell function has been investigated in in vivo models of neurodegeneration (Serpe et al., 1999; Yoles et al., 2001; Sroga et al., 2003; Frenkel et al., 2005; Sanders and Jones, 2006; Liesz et al., 2009; Beck et al., 2010; Xin et al., 2011). However, it should be noted that many of these studies were performed in immune compromised animals and as such, it could be argued that the observed effects may be due to $\mathrm{T}$ cell independent broader effects of development in the absence of a functioning adaptive immune system (Rook et al., 2011). With regard to T cell subtypes and neuroprotection, recent studies have implicated Treg cells as being the key lymphocyte population involved in neuroprotection in experimental stoke (Liesz et al., 2009 but also see Ren et al., 2011). 
Similarly, in experimental autoimmune encephalitis (EAE) models, neurons have been proposed to induce Treg cells from encephalitogenic T cells and these Treg cells function to supress EAE (Liu et al., 2006). In addition to Treg, Th2 cells have been suggested to play a role in neuroprotection (Hendrix and Nitsch, 2007; Yong and Marks, 2010) but there are discrepancies as to whether this occurs in a contact-dependent (Roy et al., 2007) or contactindependent manner (Wolf et al., 2002). Our findings support the suggestion that T cells can be neuroprotective and that protection is via soluble factors; however which $\mathrm{T}$ cell subtype is responsible for these effects under our experimental conditions requires further investigation.

\subsection{Lymphocyte-mediated neuroprotection is contact-independent.}

Having established that lymphocyte preparations are neuroprotective in a contactindependent manner, we also sought to identify the underlying mechanisms. We confirmed that soluble mediators were responsible for the observed neuroprotection as lymphocyteconditioned media was protective against KA-induced and OGD-induced toxicity. Furthermore, as boiling the lymphocyte-conditioned media abolished this neuroprotection, we conclude that protein(s) within the media underlie this neuroprotection. We performed an array of 40 cytokines in order to try and identify the cytokine(s) potentially underlying this neuroprotection with our results revealing a robust increase in IL-16 levels only in media conditioned in the presence of lymphocytes with all other cytokines investigated being at similar levels in all three conditions examined. IL-16 was originally described as a T cell chemoattractant factor but it is now accepted as a cytokine as it lacks the classic chemokine motifs (Center and Cruickshank, 1982; Cruickshank and Center, 1982; Bacon et al., 2002). In $\mathrm{T}$ cells, IL-16 has been shown increase intracellular $\mathrm{Ca}^{2+}$, inositol 1,4,5-triphosphate levels and stress activated protein kinase activity as well as stimulate the release of proinflammatory cytokines (Cruickshank et al., 1991; Krautwald, 1998; Zhang et al., 2008); whether IL-16 
elicits similar changes in CNS cell types remains unknown. However, a neuronal IL-16 has also been described and it is proposed that this neuronal form may play some autocrine function within the CNS (Kurschner and Yuzaki, 1999) by interacting with CD4 which has been shown to be expressed in neurons (Omri et al., 1994). Regarding the role of IL-16 in CNS diseases, evidence exists relating increased levels of IL-16 to disease severity in the EAE mouse model (Skundric et al., 2005) and increased microglial expression following trimethyltin neurotoxicity (Guo et al., 2004) indicating that elevated IL-16 levels are linked to detrimental events. In contrast to this, recent evidence suggests that IL-16 may play a neuroprotective role by interacting with its binding partner, CD4 and its co-receptor CCR5 as these have been shown to be expressed in several cell types within the CNS (Omri et al., 1994, Sorce et al., 2011). Indeed, CCR5 has been shown to be upregulated by a number of neurotoxic insults including kainic acid (Chen et al., 2003). Furthermore, motor neuron death is accelerated in the absence of CCR5 (Gamo et al., 2008) and CCR5 deficient mice have reduced infarct size indicating a protective role of this receptor (Sorce et al., 2010) but whether this is mediated via glia cells or a direct action on neurons is unknown. Therefore it remains speculation as to whether the neuroprotection observed in the present study is mediated via IL-16 acting directly on cells within the OSC or via stimulating the release of other factors from lymphocytes not detected in our array but our data indicates that the neuroprotective effects revealed in this study involves IL-16 but the exact mechanisms require further investigation.

\subsection{Neuroprotection requires astrocytic activation and MAPK inhibition.}

Having identified a potential specific soluble mediator that underlies the lymphocytemediated neuroprotection under our experimental conditions, we then chose to determine whether they interacted with a specific cell type within OSCs to induce the neuroprotection. 
OSCs are made up of a heterologous population of cell types including astrocytes, microglia and neurons. Hence, due to the recent increase in our understanding of astrocytes function within the CNS under both physiological and pathophysiological conditions (Bélanger and Magistretti, 2009; Rodriguez and Verkhratsky, 2011) and having established that astrocytes were involved in the neuroprotection observed against KA-induced neurotoxicity in OSCs in a previous study (Greenwood and Bushell, 2010), we investigated whether inhibition of astrocytic activity would alter the lymphocyte-mediated neuroprotection using techniques established in our laboratory (Greenwood and Bushell, 2010; Gan et al., 2011). Inhibition of astrocytic activity using the glial toxin, FAc, abolishes lymphocyte-mediated neuroprotection against KA-induced neurotoxicity but not in the OGD model. Until recently, the primary role of astrocytes in the normal brain was thought to be maintaining the microenvironment of neurons by performing roles including glutamate uptake and recycling, $\mathrm{pH}$ and $\mathrm{K}^{+}$buffering as well as supply of energy substrates (Bélanger and Magistretti, 2009; Rodriguez and Verkhratsky, 2011) whereas it is now proposed that astrocytes can play a key role in modulating synaptic transmission and plasticity (Bélanger and Magistretti, 2009; Perea et al., 2009; Barker and Ullian, 2010; Rodriguez and Verkhratsky, 2011). Furthermore, astrocytes have recently come under scrutiny regarding their role in neurodegeneration associated with certain CNS disorders including Alzheimer's disease and Parkinson's disease (Bélanger and Magistretti, 2009; Halliday and Stevens, 2011; Rodriguez and Verkhratsky, 2011). However, there is debate as to whether astrocytes are either beneficial or detrimental in CNS diseases and this may depend on how far the disease has progressed and / or on which mediators are released at that stage of the disease. Astrocytes are capable of releasing anti- and / or proinflammatory mediators and it may depend on the relative relationship of these which determines the eventual contribution of astrocytes to the disease. Under our experimental conditions, astrocytes clearly play a role in the observed neuroprotection against KA-induced 
toxicity as shown by the loss of neuroprotection when astrocytic function is inhibited using FAc. The ability of astrocytes to release neurotrophins is thought to contribute to their role in neuroprotection with for example, BDNF and glial derived neurotrophic factor (GDNF) known to be neuroprotective in models of neurodegenerative disorders for many years (Spina et al.,1992; Tomac et al., 1995). Indeed, GDNF has been the subject of intense investigation in recent times regarding its potential therapeutic use in Parkinson's disease (Mickiewicz et al., 2011; Safi et al., 2011). However, whether astrocytically released neurotrophins do indeed underlie the lymphocyte-mediated neuroprotection in the present study requires further investigation especially as it has been suggested that $\mathrm{T}$ cell induced release of neurotrophins from astrocytes is contact-dependent (Roy et al., 2007). In contrast to the role astrocytes play in lymphocyte-mediated neuroprotection against KA-induced toxicity, our data indicates that astrocytes do not contribute to lymphocyte-mediated protection against OGD-induced toxicity. The sensitivity of astrocytes to ischaemic insults has long been an area of debate with astrocytes from different brain regions showing differential sensitivity to ischaemia and in vitro models of ischaemia revealing that despite both astrocytes and neurons being sensitive to OGD, astrocytic death is delayed in comparison to neuronal death (Zhao and Flavin, 2000; Xu et al., 2001; Giffard and Swanson, 2005; Ouyang et al., 2007). In contrast, astrocytic dysfunction is proposed to contribute to ischaemia-induced loss of neurons in in vivo models of forebrain ischaemia (Chen et al., 2005; Giffard and Swanson, 2005). This divergence in the role of astrocytes may indicate that OGD toxicity is not cell type selective whereas KA induces toxicity primarily in neurons and therefore astrocytes do not contribute to the neuroprotection against OGD because they themselves are dysfunctional or dead. Despite this, it is clear that lymphocytes are protective in two different in vitro neurodegenerative models and the soluble mediators involved may have direct actions resulting in neuroprotection either directly or indirectly via astrocytes. 
Having shown that lymphocytes were neuroprotective in two different in vitro neurodegenerative models, we sought to investigate the signalling pathways that may underlie this. We focussed our efforts on the MAPK and PI3K pathways as it is well established that cytokines can modulate both these pathways (Schieven, 2009; Kim and Choi, 2010; Kim and Suresh, 2013) and that modulators of the MAPK pathway in particular are therapeutic targets for the CNS neurodegenerative disorders (Cuny, 2009; Yasuda et al., 2011). Exposure of OSCs to lymphocytes reduced p38 MAPK and ERK activity whereas no effect on JNK 1/2 activity was observed. Significantly, when the reduction in MAPK activity was mimicked using pharmacological inhibitors, a similar level of neuroprotection was observed. As the lymphocyte-mediated neuroprotection is contact-independent, these data indicate that the soluble mediators released by lymphocytes results in this reduction in MAPK activity. Of the potential candidates, this reduction in activity would suggest that neurotrophins do not underlie the protection as studies have shown they generally lead to the activation of MAPK pathways via Trk receptors (Ouwens et al., 2002; Shi et al., 2005; Reichardt, 2006). Despite this, it is interesting to note that the neuroprotection mediated by lymphocytes involves an inhibition of p38 MAPK as increased p38 MAPK activity has been associated with several CNS neurodegenerative disorders and inhibitors of its activity are proposed as therapeutic drugs for CNS disorders (Cuny, 2009; Yasuda et al., 2011). In contrast to the role of p38 MAPK in neurodegeneration, it is generally thought that ERK activation is neuroprotective (Mehta et al., 2007) however there is a growing body of evidence which suggests that increased and /or prolonged ERK activation may indeed contribute to cell death and CNS diseases (Zhuang and Schnellmann, 2006). Hence it is feasible that a reduction in ERK activity as observed in the present study would be advantageous in terms of cell survival. Finally, our finding that JNK $1 / 2$ activity is 
unaffected by exposure to lymphocytes suggests that modulation of this pathway does not appear to contribute to the observed lymphocyte mediated neuroprotection.

\section{Conclusions}

In conclusion, our data demonstrates that lymphocytes are neuroprotective against KAinduced and OGD-induced toxicity under our experimental conditions and that this is independent of $\mathrm{T}$ cell activation. We propose that this neuroprotection is mediated indirectly by the action of a soluble mediator, likely to be IL-16, on astrocytes and the inhibition of ERK and p38 MAPK activities. These data, along with previous studies, suggest a neuroprotective role for lymphocytes in models of neuronal death or injury, and that lymphocytes may play multiple roles in CNS disorders. However, further investigation is required to decipher when and why the divergence between their proposed protective or detrimental roles occur in vivo. 


\section{Acknowledgements}

Thanks to Dr. Sam M Greenwood for his expertise regarding OSCs, Dr. Andrew Paul and Dr. Carly Gamble for their help in western blotting and Dr. Karen Bryson, Dr. Robert Benson and Dr. Agapitos Patakas for their help and advice with the preparation of lymphocytes. RS was funded by a Scottish Funding Council studentship. The authors declare that they have no competing interests. 


\section{References}

Bacon, K., Baggiolini, M., Broxmeyer, H., Horuk, R., Lindley, I., Mantovani, A., Maysushima, K., Murphy, P., Nomiyama, H., Oppenheim, J., Rot, A., Schall, T., Tsang, M., Thorpe, R., Van Damme, J., Wadhwa, M., Yoshie, O., Zlotnik, A., Zoon K., 2002. Chemokine/chemokine receptor nomenclature. J. Interferon. Cytokine Res. 22, 1067-8. Barker, A.J., Ullian, E.M., 2010. Astrocytes and synaptic plasticity. Neuroscientist 16, 4050.

Barnum, C.J., Tansey, M.G., 2010. Modeling neuroinflammatory pathogenesis of Parkinson's disease. Prog. Brain. Res. 184,113-32.

Batoulis, H., Recks, M.S., Addicks, K., Kuerten, S., 2011. Experimental autoimmune encephalomyelitis--achievements and prospective advances. APMIS 119, 819-30.

Becher, B., Bechmann, I., Greter, M., 2006. Antigen presentation in autoimmunity and CNS inflammation: how T lymphocytes recognize the brain. J. Mol. Med. 84, 532-543.

Beck, K.D., Nguyen, H.X., Galvan, M.D., Salazar, D.L., Woodruff, T.M., Anderson, A.J., 2010. Quantitative analysis of cellular inflammation after traumatic spinal cord injury: evidence for a multiphasic inflammatory response in the acute to chronic environment. Brain $133,433-47$.

Bélanger, M., Magistretti, P.J., 2009. The role of astroglia in neuroprotection. Dialogues Clin. Neurosci. 11, 281-95.

Center, D.M., Cruickshank, W., 1982. Modulation of lymphocyte migration by human lymphokines. I. Identification and characterization of chemoattractant activity for lymphocytes from mitogen-stimulated mononuclear cells. J. Immunol. 128, 2563-8. Chen, Z., Yu, S., Bakhiet, M., Winblad, B., Zhu, J., 2003. The chemokine receptor CCR5 is not a necessary inflammatory mediator in kainic acid-induced hippocampal injury: evidence for a compensatory effect by increased CCR2 and CCR3. J. Neurochem. 86, 61-8. 
Chen, L.W., Yung, K.L., Chan Y.S., 2005. Reactive astrocytes as potential manipulation targets in novel cell replacement therapy of Parkinson's disease. Curr. Drug Targets 6, 82133.

Cohen, I.R., Schwartz M., 1999. Autoimmune maintenance and neuroprotection of the central nervous system. J. Neuroimmunol. 100, 111-114.

Cruickshank, W., Center, D.M., 1982. Modulation of lymphocyte migration by human lymphokines. II. Purification of a lymphocyte factor (LCF). J. Immunol. 128, 2569-74. Cuny, G.D., 2009. Kinase inhibitors as potential therapeutics for acute and chronic neurodegenerative conditions. Curr. Pharm. Des. 15, 3919-39. de Bilbao F., Arsenijevic D., Moll T., Garcia-Gabay I., Vallet P., Langhans W. and Dittel, B.N., 2008. CD4 T cells: Balancing the coming and going of autoimmune-mediated inflammation in the CNS. Brain Behav. Immun. 22, 421-430.

Engelhardt, B., 2006 Molecular mechanisms involved in T cell migration across the bloodbrain barrier. J. Neural. Transm. 113, 477-485.

Fee, D., Crumbaugh A., Jacques T., Herdrich B., Sewell D., Auerbach D., Piaskowski S., Hart M.N., Sandor M., Fabry Z., 2003. Activated/effector CD4+ T cells exacerbate acute damage in the central nervous system following traumatic injury. J. Neuroimmunol. 136, 5466.

Frenkel, D., Huang, Z., Maron, R., Koldzic, D.N., Moskowitz, M.A., Weiner, H.L., 2005. Neuroprotection by IL-10-producing MOG CD4+ T cells following ischemic stroke. J. Neurol. Sci. 233, 125-32. 
Fumagalli, S., Coles, J.A., Ejlerskov, P., Ortolano, F., Bushell, T.J., Brewer, J.M., De Simoni, M.G., Dever, G., Garside, P., Maffia, P., Carswell, H.V., 2011. In vivo real-time multiphoton imaging of T lymphocytes in the mouse brain after experimental stroke. Stroke 42, 1429-36. Gamo, K., Kiryu-Seo, S., Konishi, H., Aoki, S., Matsushima, K., Wada, K., Kiyama, H., 2008. G-protein-coupled receptor screen reveals a role for chemokine receptor CCR5 in suppressing microglial neurotoxicity. J. Neurosci. 28, 11980-8.

Gan, J., Greenwood, S.M., Cobb, S.R., Bushell T.J., 2011. Indirect modulation of neuronal excitability and synaptic transmission in the hippocampus by activation of proteinaseactivated receptor-2. Br. J. Pharmacol. 163, 984-94.

Garg, S.K., Banerjee R., Kipnis J., 2008. Neuroprotective immunity: T cell-derived glutamate endows astrocytes with a neuroprotective phenotype. J. Immunol. 180, 3866-3873.

Giffard, R.G., Swanson R.A., 2005. Ischemia-induced programmed cell death in astrocytes. Glia 50, 299-306.

Grammas, P., 2011. Neurovascular dysfunction, inflammation and endothelial activation: implications for the pathogenesis of Alzheimer's disease. J. Neuroinflamm. 8, 26.

Greenwood, S.M., Bushell, T.J., 2010. Astrocytic activation and an inhibition of MAP kinases are required for proteinase-activated receptor-2-mediated protection from neurotoxicity. J. Neurochem. 113, 1471-80.

Guo, L.H., Mittelbronn, M., Brabeck, C., Mueller, C.A., Schluesener, H.J. 2004. Expression of interleukin-16 by microglial cells in inflammatory, autoimmune, and degenerative lesions of the rat brain. J. Neuroimmunol. 146, 39-45.

Halliday, G.M., Stevens, C.H., 2011. Glia: initiators and progressors of pathology in Parkinson's disease. Mov. Disord. 26, 6-17.

Hendrix, S., Nitsch, R., 2007. The role of T helper cells in neuroprotection and regeneration. J. Neuroimmunol. 184, 100-12. 
Hickey, W.F., Hsu, B.L., Kimura, H., 1991. T-lymphocyte entry into the central nervous system. J. Neurosci. Res. 28, 254-260.

Hickey, W.F., 1999. Leukocyte traffic in the central nervous system: the participants and their roles. Semin. Immunol. 11, 125-137.

Kim, E.K., Choi, E.J., 2010. Pathological roles of MAPK signaling pathways in human diseases. Biochim. Biophys. Acta. 1802, 396-405.

Kim, E.H., Suresh, M., 2013. Role of PI3K/Akt signaling in memory CD8 T cell differentiation. Front. Immunol. 4, 20. doi: 10.3389/fimmu.2013.00020.

Kipnis, J., Yoles, E., Porat, Z., Cohen, A., Mor, F., Sela, M., Cohen, I.R., Schwartz M., 2000. $\mathrm{T}$ cell immunity to copolymer 1 confers neuroprotection on the damaged optic nerve: possible therapy for optic neuropathies. Proc. Natl. Acad. Sci. USA. 97, 7446-7451.

Kipnis, J., Cohen, H., Cardon, M., Ziv, Y., Schwartz, M., 2004. T cell deficiency leads to cognitive dysfunction: implications for therapeutic vaccination for schizophrenia and other psychiatric conditions. Proc. Natl. Acad. Sci. U S A. 101, 8180-5.

Kurschner, C., Yuzaki, M., 1999. Neuronal interleukin-16 (NIL-16): a dual function PDZ domain protein. J. Neurosci. 19, 7770-80.

Larochelle, C., Alvarez, J.I., Prat, A., 2011. How do immune cells overcome the blood-brain barrier in multiple sclerosis? FEBS Lett. 585, 3770-80.

Liesz, A., Suri-Payer, E., Veltkamp, C., Doerr, H., Sommer, C., Rivest, S., Giese, T., Veltkamp, R., 2009. Regulatory T cells are key cerebroprotective immunomodulators in acute experimental stroke. Nat. Med. 15, 192-9.

Liu, Y., Teige, I., Birnir, B., Issazadeh-Navikas, S., 2006. Neuron-mediated generation of regulatory T cells from encephalitogenic T cells suppresses EAE. Nat. Med. 12, 518-25.

Mickiewicz, A.L., Kordower, J.H., 2011. GDNF family ligands: a potential future for Parkinson's disease therapy. CNS Neurol. Disord. Drug Targets 10, 703-11. 
Mehta, S.L., Manhas N., Raghubir, R., 2007. Molecular targets in cerebral ischemia for developing novel therapeutics. Brain Res. Rev. 54, 34-66.

Moalem, G., Gdalyahu, A., Shani, Y., Otten, U., Lazarovici, P., Cohen, I.R., Schwartz M., 2000. Production of neurotrophins by activated T cells: implications for neuroprotective autoimmunity. J. Autoimmun. 15, 331-345.

Noraberg, J., Poulsen, F.R., Blaabjerg, M., Kristensen, B.W., Bonde, C., Montero, M., Meyer, M., Gramsbergen, J.B., Zimmer J., 2005. Organotypic hippocampal slice cultures for studies of brain damage, neuroprotection and neurorepair. Curr. Drug Targets CNS. Neurol. Disord. 4, 435-52.

Omri, B., Crisanti, P., Alliot, F., Marty, M.C., Rutin, J., Levallois, C., Privat, A., Pessac, B., 1994. CD4 expression in neurons of the central nervous system. Int. Immunol. 6, 377-85.

Ouwens, D.M., de Ruiter, N.D., van der Zon, G.C., Carter, A.P., Schouten, J., van der Burgt, C., Kooistra, K., Bos, J.L., Maassen, J.A., van Dam, H., 2002. Growth factors can activate ATF2 via a two-step mechanism: phosphorylation of Thr71 through the Ras-MEK-ERK pathway and of Thr69 through RalGDS-Src-p38. EMBO J. 21, 3782-93.

Ouyang, Y.B., Voloboueva, L.A., Xu, L.J., Giffard R.G., 2007. Selective dysfunction of hippocampal CA1 astrocytes contributes to delayed neuronal damage after transient forebrain ischemia. J. Neurosci. 27, 4253-60.

Perea, G., Navarrete, M., Araque, A., 2009. Tripartite synapses: astrocytes process and control synaptic information. Trends Neurosci. 32, 421-31.

Ponomarev, E.D., Novikova, M., Yassai, M., Szczepanik, M., Gorski, J., Dittel B.N., 2004. Gamma delta $\mathrm{T}$ cell regulation of IFN-gamma production by central nervous systeminfiltrating encephalitogenic $\mathrm{T}$ cells: correlation with recovery from experimental autoimmune encephalomyelitis. J. Immunol. 173, 1587-1595. 
Ponomarev, E.D., Maresz, K., Tan, Y., Dittel, B.N., 2007. CNS-derived interleukin-4 is essential for the regulation of autoimmune inflammation and induces a state of alternative activation in microglial cells. J. Neurosci. 27, 10714-10721.

Qian, L., Flood, P.M., Hong, J.S., 2010. Neuroinflammation is a key player in Parkinson's disease and a prime target for therapy. J. Neural. Transm. 117, 971-9.

Reichardt, L.F., 2006. Neurotrophin-regulated signalling pathways. Philos. Trans. R. Soc. Lond. B. Biol. Sci. 361, 1545-64.

Ren, X., Akiyoshi, K., Vandenbark, A.A., Hurn, P.D., Offner, H., 2011. CD4+FoxP3+ regulatory T-cells in cerebral ischemic stroke. Metab. Brain Dis. 26, 87-90.

Rodríguez, J.J., Verkhratsky, A., 2011. Neuroglial roots of neurodegenerative diseases? Mol. Neurobiol. 43, 87-96.

Rook, G.A., Lowry, C.A., Raison, C.L., 2011. Lymphocytes in neuroprotection, cognition and emotion: is intolerance really the answer? Brain Behav. Immun. 25, 591-601.

Roy, A., Liu, X., Pahan K., 2007. Myelin basic protein-primed T cells induce neurotrophins in glial cells via alphavbeta3 integrin. J. Biol. Chem. 282, 32222-32.

Safi, R., Gardaneh, M., Panahi, Y., Maghsoudi, N., Zaefizadeh, M., Gharib E., 2012. Optimized quantities of GDNF overexpressed by engineered astrocytes are critical for protection of neuroblastoma cells against 6-OHDA toxicity. J. Mol. Neurosci. 46, 654-65.

Sanders, V.M., Jones K.J., 2006. Role of immunity in recovery from a peripheral nerve injury. J. Neuroimmune Pharmacol. 1, 11-9.

Schieven, G.L., 2009. The p38alpha kinase plays a central role in inflammation. Curr. Top. Med. Chem. 9,1038-48.

Schwartz, M., 2005. T-cell-based vaccination against neurodegeneration: a new therapeutic approach. Retina 25, S33-S35. 
Serpe, C.J., Kohm, A.P., Huppenbauer, C.B., Sanders, V.M., Jones, K.J., 1999. Exacerbation of facial motoneuron loss after facial nerve transection in severe combined immunodeficient (SCID) mice. J. Neurosci. 19, RC7.

Shaked, I., Tchoresh, D., Gersner, R., Meiri, G., Mordechai, S., Xiao, X., Hart, R.P., Schwartz, M., 2005. Protective autoimmunity: interferon-gamma enables microglia to remove glutamate without evoking inflammatory mediators. J. Neurochem. 92, 997-1009.

Shi, G.X., Han J., Andres, D.A., 2005. Rin GTPase couples nerve growth factor signaling to p38 and b-Raf/ERK pathways to promote neuronal differentiation. J. Biol. Chem. 280, 37599-609.

Skundric, D.S., Zhou, W., Cruikshank, W.W., Dai, R., 2005. Increased levels of bioactive IL16 correlate with disease activity during relapsing experimental autoimmune encephalomyelitis (EAE). J. Autoimmun. 25, 206-14.

Sorce, S., Bonnefont, J., Julien, S., Marq-Lin, N., Rodriguez, I., Dubois-Dauphin, M. Krause, K.H., 2010. Increased brain damage after ischaemic stroke in mice lacking the chemokine receptor CCR5. Br. J. Pharmacol.160, 311-21.

Sorce, S., Myburgh, R., Krause, K.H., 2011. The chemokine receptor CCR5 in the central nervous system. Prog Neurobiol. 93, 297-311.

Spina, M.B., Hyman, C., Squinto, S., Lindsay R.M., 1992. Brain-derived neurotrophic factor protects dopaminergic cells from 6-hydroxydopamine toxicity. Ann. N. Y. Acad. Sci. 648, 348-50.

Sroga, J.M., Jones, T.B., Kigerl, K.A., McGaughy, V.M., Popovich, P.G., 2003. Rats and mice exhibit distinct inflammatory reactions after spinal cord injury. J. Comp. Neurol. 462, $223-40$.

Stadelmann, C., 2011. Multiple sclerosis as a neurodegenerative disease: pathology, mechanisms and therapeutic implications. Curr. Opin. Neurol. 24, 224-9. 
Tomac, A., Lindqvist, E., Lin, L.F., Ogren, S.O., Young, D., Hoffer, B.J., Olson, L., 1995. Protection and repair of the nigrostriatal dopaminergic system by GDNF in vivo. Nature 373, $335-9$.

Wang, Q., Yu, S., Simonyi, A., Sun, G.Y., Sun, A.Y., 2005. Kainic acid-mediated excitotoxicity as a model for neurodegeneration. Mol. Neurobiol. 31, 3-16.

Wolf, S.A., Fisher, J., Bechmann, I., Steiner, B., Kwidzinski, E., Nitsch, R., 2002. Neuroprotection by T-cells depends on their subtype and activation state. J. Neuroimmunol. $133,72-80$.

Wolf, S.A., Steiner, B., Akpinarli, A., Kammertoens, T., Nassenstein, C., Braun, A., Blankenstein, T., Kempermann, G., 2009. CD4-positive $\mathrm{T}$ lymphocytes provide a neuroimmunological link in the control of adult hippocampal neurogenesis. J. Immunol. 182, $3979-84$.

Xin, J., Wainwright, D.A., Mesnard, N.A., Serpe, C.J., Sanders, V.M., Jones, K.J., 2011. IL10 within the CNS is necessary for CD4+ T cells to mediate neuroprotection. Brain Behav. Immun. 25, 820-9.

Xu, L., Sapolsky, R.M., Giffard, R.G., 2001. Differential sensitivity of murine astrocytes and neurons from different brain regions to injury. Exp. Neurol. 169, 416-24.

Yasuda, S., Sugiura, H., Tanaka, H., Takigami, S., Yamagata, K., 2011. p38 MAP kinase inhibitors as potential therapeutic drugs for neural diseases. Cent. Nerv. Syst. Agents Med. Chem. 11, 45-59.

Yoles, E., Hauben, E., Palgi, O., Agranov, E., Gothilf, A., Cohen, A., Kuchroo, V., Cohen, I.R., Weiner, H., Schwartz, M. 2001. Protective autoimmunity is a physiological response to CNS trauma. J. Neurosci. 21, 3740-8.

Yong, V.W., Marks, S., 2010. The interplay between the immune and central nervous systems in neuronal injury. Neurology 74 Suppl 1,S9-S16. 
Zhao, G., Flavin, M.P., 2000. Differential sensitivity of rat hippocampal and cortical astrocytes to oxygen-glucose deprivation injury. Neurosci. Lett. $285,177-80$.

Zheng, X.Y., Zhang H.L., Luo Q., Zhu, J., 2011. Kainic acid-induced neurodegenerative model: potentials and limitations. J. Biomed. Biotechnol. 2011:457079.

Zhuang, S., Schnellmann, R.G., 2006. A death-promoting role for extracellular signalregulated kinase. J. Pharmacol. Exp. Ther. 319, 991-7.

Ziv, Y., Ron, N., Butovsky, O., Landa, G., Sudai, E., Greenberg, N., Cohen, H., Kipnis J., Schwartz, M., 2006. Immune cells contribute to the maintenance of neurogenesis and spatial learning abilities in adulthood. Nat. Neurosci. 9, 268-75. 


\section{Figure Legends}

Fig 1. Lymphocytes do not induce neurotoxicity in organotypic slice cultures. A. Representative images showing propidium iodide fluorescence $18 \mathrm{~h}$ after exposure to KA (30 $\mu \mathrm{M}$ and $300 \mu \mathrm{M}, 1 \mathrm{~h}$ ) or mixed lymphocytes (1h). B. KA induces neuronal cell death in OSCs in a concentration-dependent manner. C. Summary illustrating the effects of lymphocyte preparations containing activated and non-activated $\mathrm{T}$ cells on neuronal survival in OSCs. Data are expressed as mean \pm S.E.M. and are normalised with respect to $3 \mathrm{mM}$ KA. $* * * \mathrm{P}<0.001$ versus control. Scale bars: $150 \mu \mathrm{m}$.

Fig 2. Lymphocyte-mediated neuroprotection against KA-induced neurotoxicity is independent of $\mathbf{T}$ cell activation state. A. Representative images illustrating cell death $18 \mathrm{~h}$ after exposure to KA alone $(300 \mu \mathrm{M}, 1 \mathrm{~h})$ or KA followed by exposure to lymphocytes containing activated or non-activated T cells $(18 \mathrm{~h})$. B. Bar chart revealing that lymphocyte preparations were ineffective against KA-induced neurotoxicity when OSCs were exposed to lymphocytes for $1 \mathrm{~h}$ post insult whereas neurotoxicty was significantly reduced in OSCs exposed to lymphocytes for $18 \mathrm{~h}$ post insult with this protection being independent of $\mathrm{T}$ cell

activation state. C. Summary showing that protection against KA-induced neurotoxicity is observed with purified T cells, independent of activation state and T cell depleted lymphocyte preparations. Data are expressed as mean \pm S.E.M. and are normalised with respect to $3 \mathrm{mM}$ KA. $* \mathrm{P}<0.05, * * \mathrm{P}<0.01, * * * \mathrm{P}<0.001$ versus control. Scale bars: $150 \mu \mathrm{m}$. 


\section{Fig 3. Soluble mediators underlie lymphocyte-mediated neuroprotection. A.}

Representative images illustrating cell death $18 \mathrm{~h}$ after exposure to KA alone (300 $\mu \mathrm{M}, 1 \mathrm{~h})$ and in the presence of lymphocyte conditioned media (LCM) or boiled LCM for $18 \mathrm{~h}$ post insult. B. Summary illustrating that LCM is neuroprotective against KA-induced toxicity and the conditioning is not dependent on the presence of OSCs. In contrast, boiled LCM or conditioned media (CM) from KA treated OSCS or primary hippocampal cultures are without effect. C. Representative array blot for IL-16 revealing a robust increase in IL-16 in LCM compared to media controls. D. Scatter plot showing IL-16 values from the primary screening of 40 cytokines. No difference was seen in the other 39 cytokines assayed. Data are expressed as mean \pm S.E.M. and are normalised with respect to $3 \mathrm{mM} \mathrm{KA}$. $* * \mathrm{P}<0.01$ versus control. \#\#\#P<0.001 versus KA + LCM. Scale bars: $150 \mu \mathrm{m}$.

Fig 4. Astrocytic activation and inhibition of MAPK activity underlies lymphocytemediated neuroprotection. A. The glial toxin, FAc $(10 \mu \mathrm{M})$ does not reduce KA-induced toxicity but abolishes LCM-mediated neuroprotection. B. Representative blots illustrating that exposure to lymphocytes reduces p-p38 MAPK and p-ERK but not total protein in OSCs. No effect on p-JNK 1/2 or total JNK was observed. C. Bar chart revealing the effect of lymphocytes on p38 MAPK, ERK and JNK 1/2 activity in OSCs. D. Summary illustrating that the pharmacological inhibition of p38 MAPK and ERK with SB203580 and U0126 is neuroprotective against KA-induced neurotoxicity whereas inhibition of PI3K was without effect on LCM-mediated neuroprotection. Data are expressed as mean \pm S.E.M. and are normalised with respect to $3 \mathrm{mM} \mathrm{KA} . * \mathrm{P}<0.05, * * \mathrm{P}<0.01$, $* * * \mathrm{P}<0.001$ versus control, \#\#\#P<0.001 versus LCM alone. Scale bars: $150 \mu \mathrm{m}$. 


\section{Fig 5. Lymphocytes are neuroprotective against OGD-induced cell death.}

A. Representative images illustrating cell death in OSCs $18 \mathrm{~h}$ after exposure to OGD (30 mins) either alone or maintained in the presence of lymphocytes. B. Summary showing that lymphocytes and LCM are protective against OGD-induced cell death, an effect which is mimicked by p38 MAPK and ERK inhibition but not by PI3K inhibition. Data are expressed as mean \pm S.E.M. and are normalised with respect to $3 \mathrm{mM}$ KA. ${ }^{*} \mathrm{P}<0.05$, $* * \mathrm{P}<0.01$, $* * * \mathrm{P}<0.001$ versus control. Scale bars: $150 \mu \mathrm{m}$. 
A

Figure 1
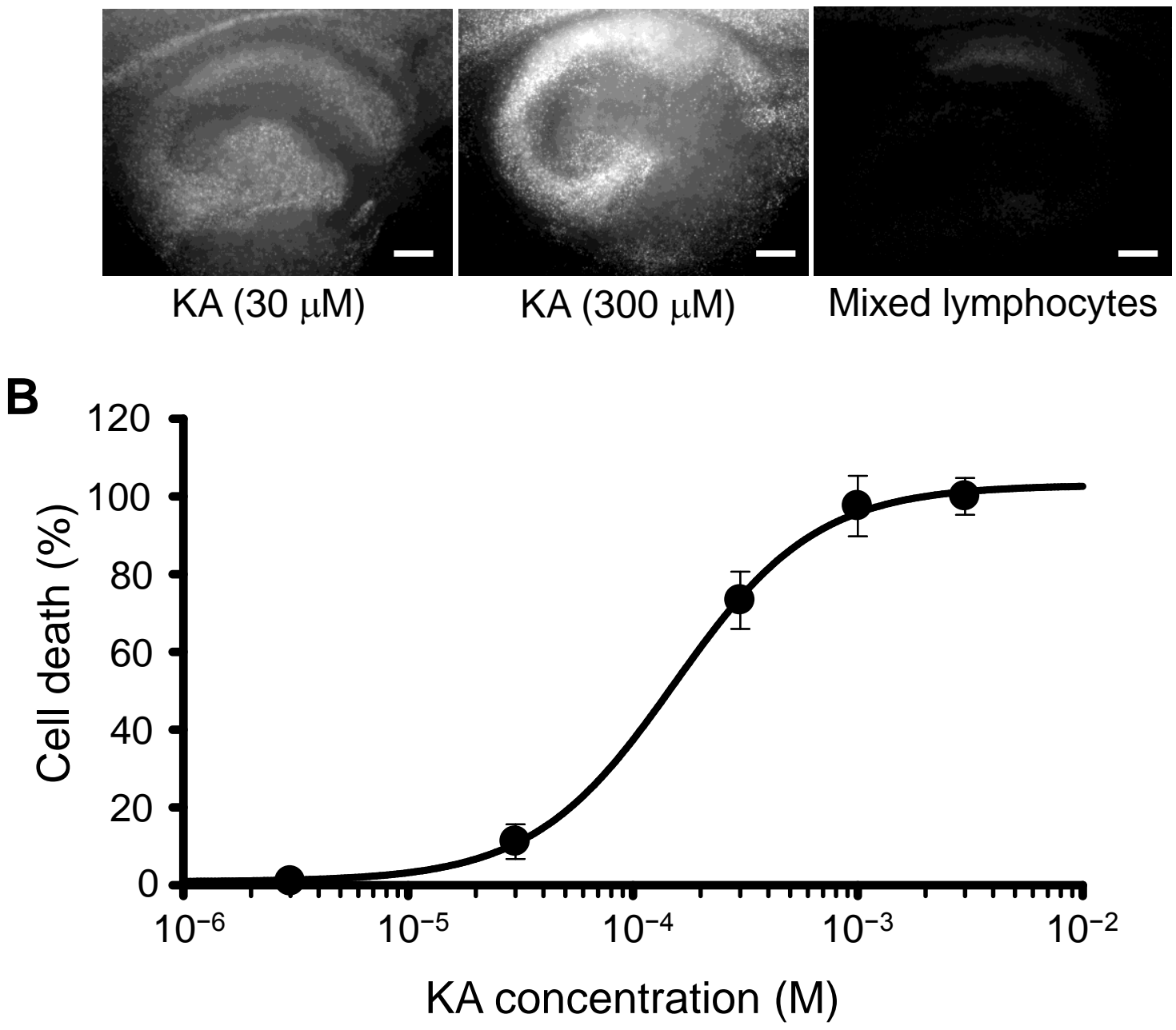

C

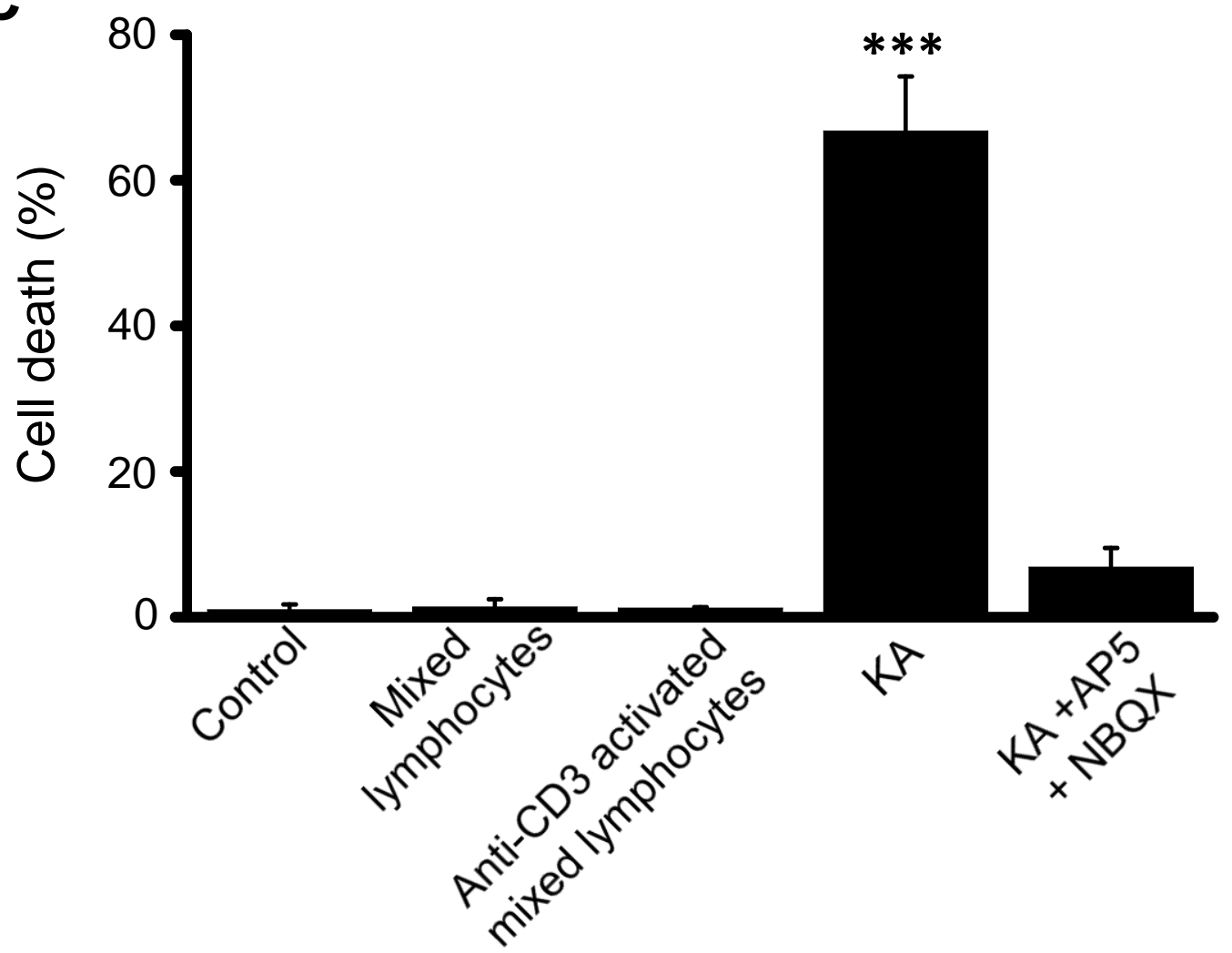


A

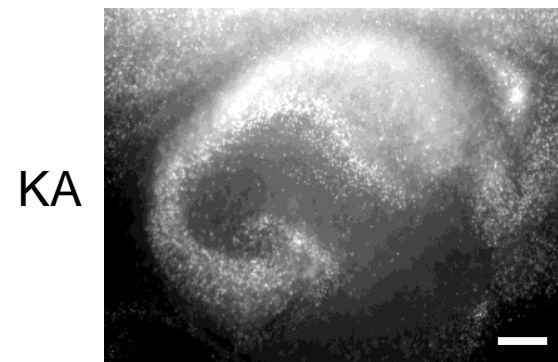

Alone

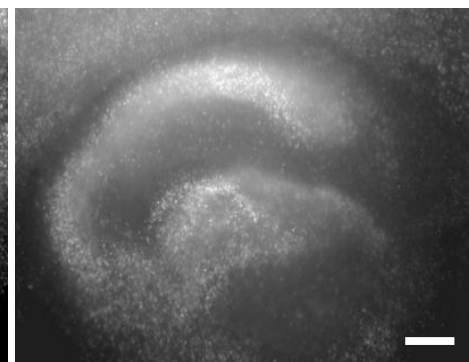

+ lymphocytes

(18 hr)

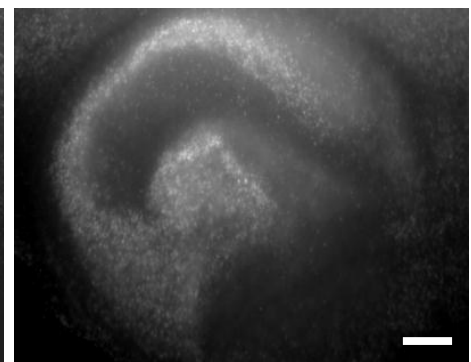

+ lymphocytes inc. activated $T$ cells (18hr)

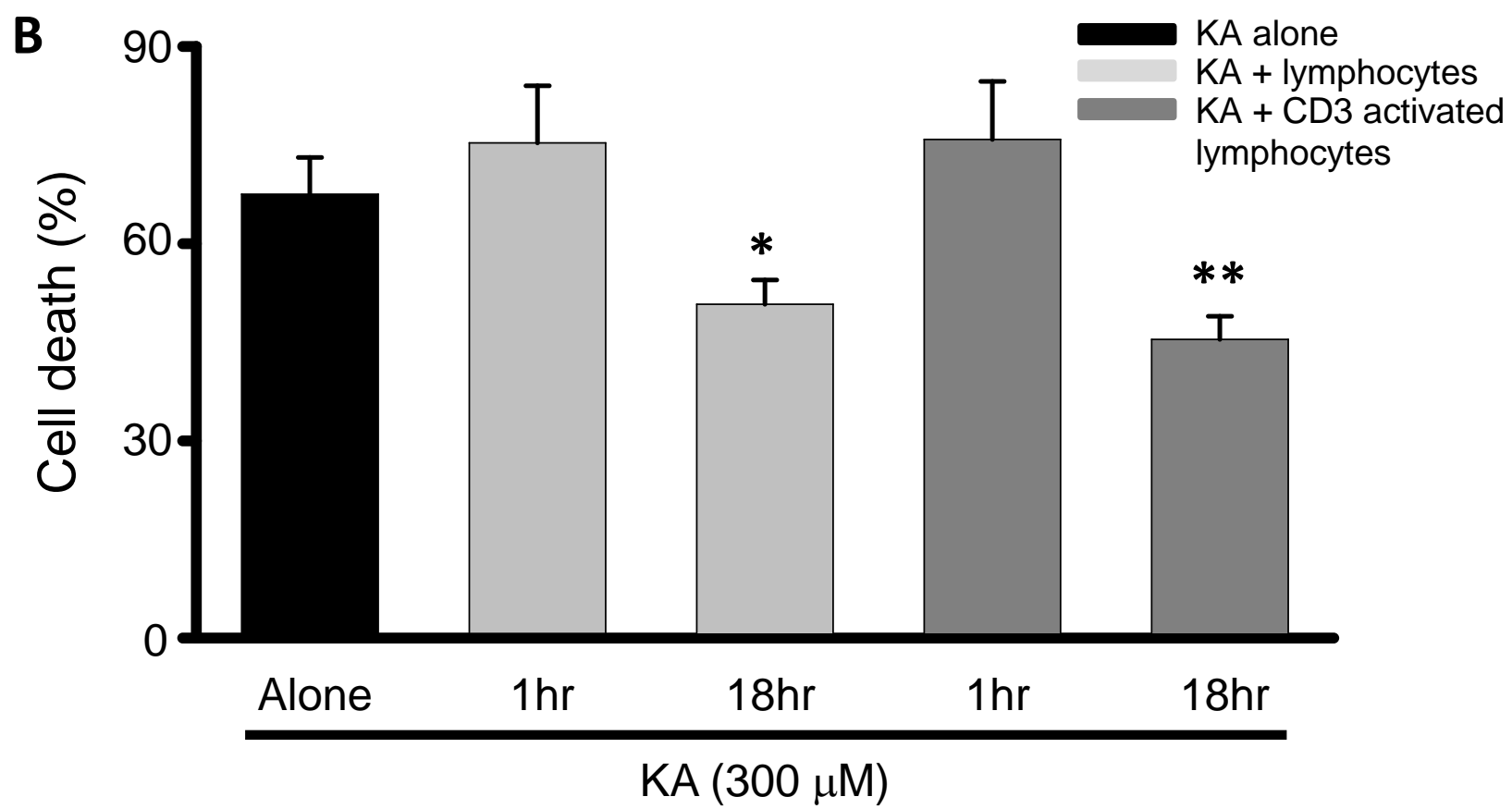

C

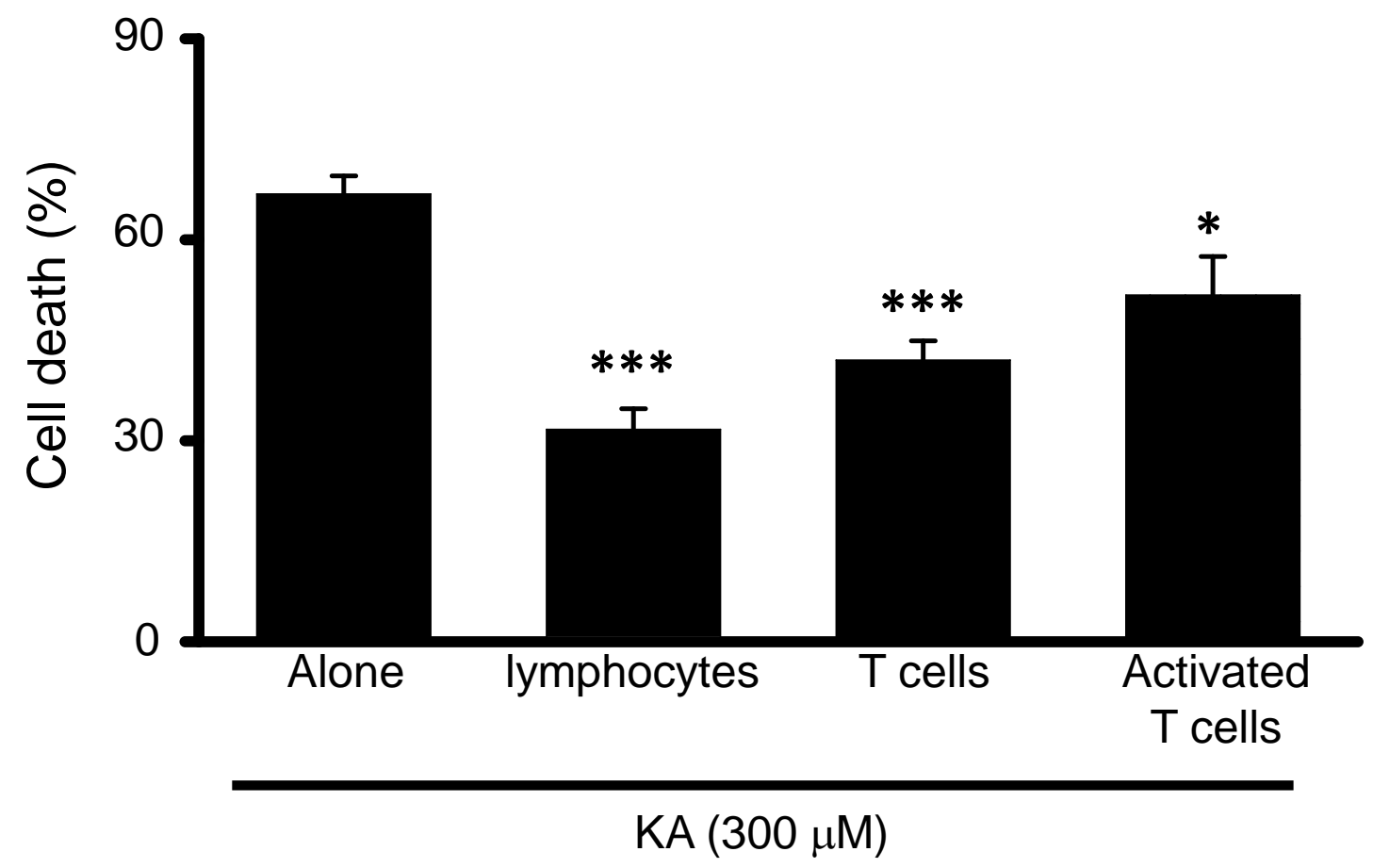


Figure 3

A

$\mathrm{KA}$

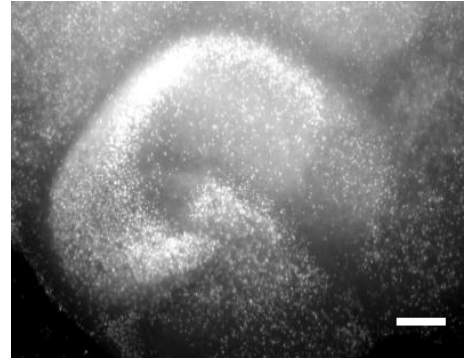

Alone

B

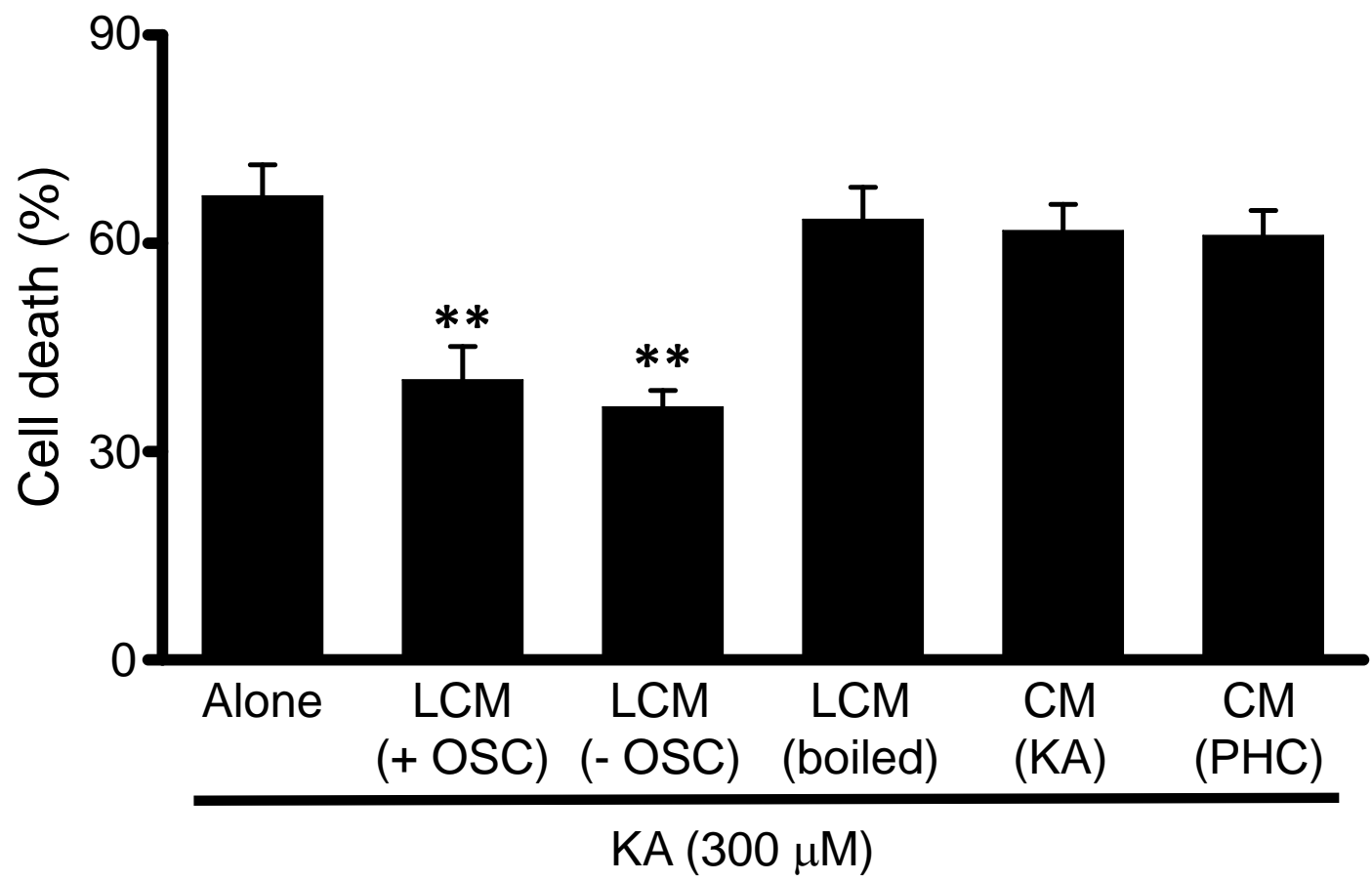

C

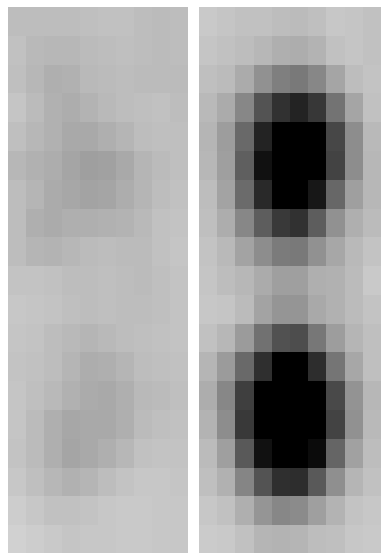

Control LCM Media

(18h)

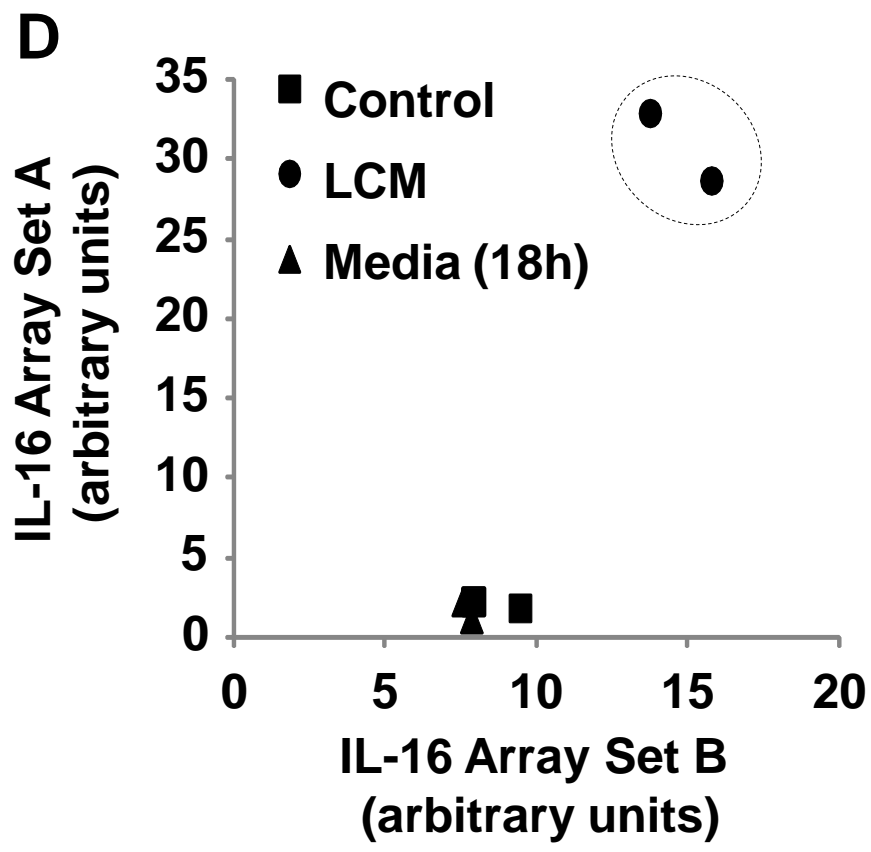


A

-lymph + lymph -lymph +lymph - lymph + lymph

Phospho

Total

p38 MAPK

ERK

JNK

B

C
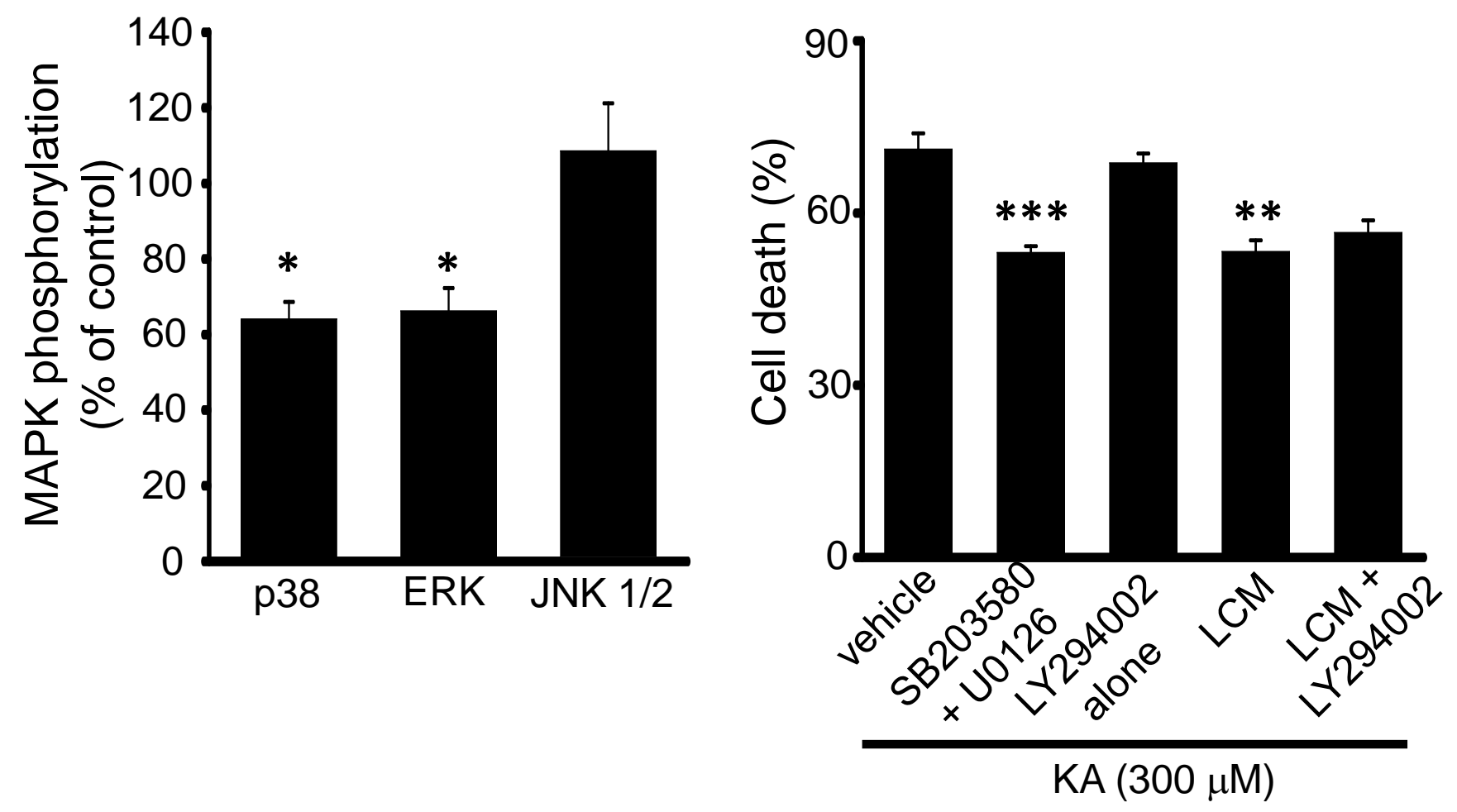

D

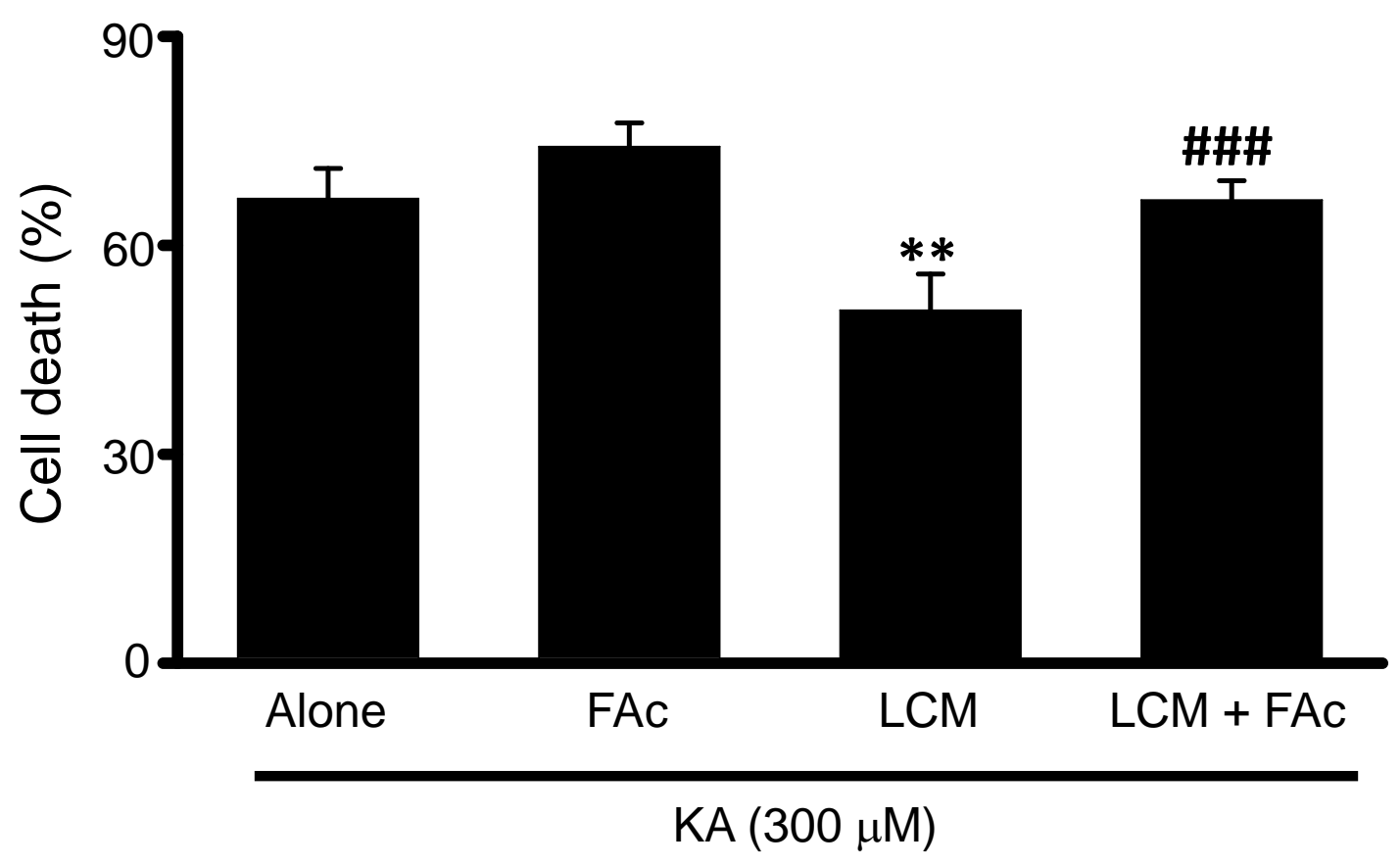


Figure 5

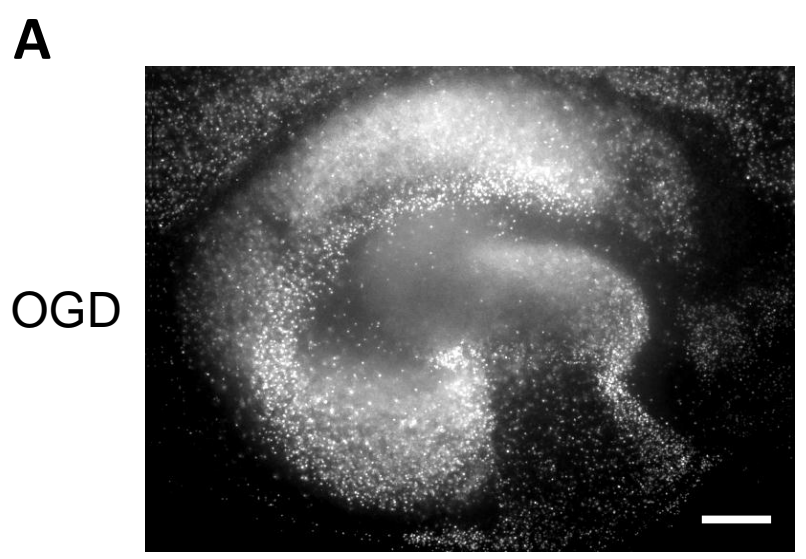

Alone

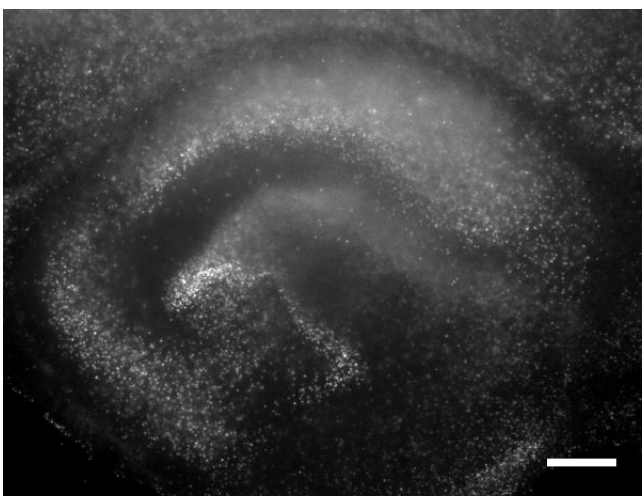

+ lymphocytes

(18 hr)

B

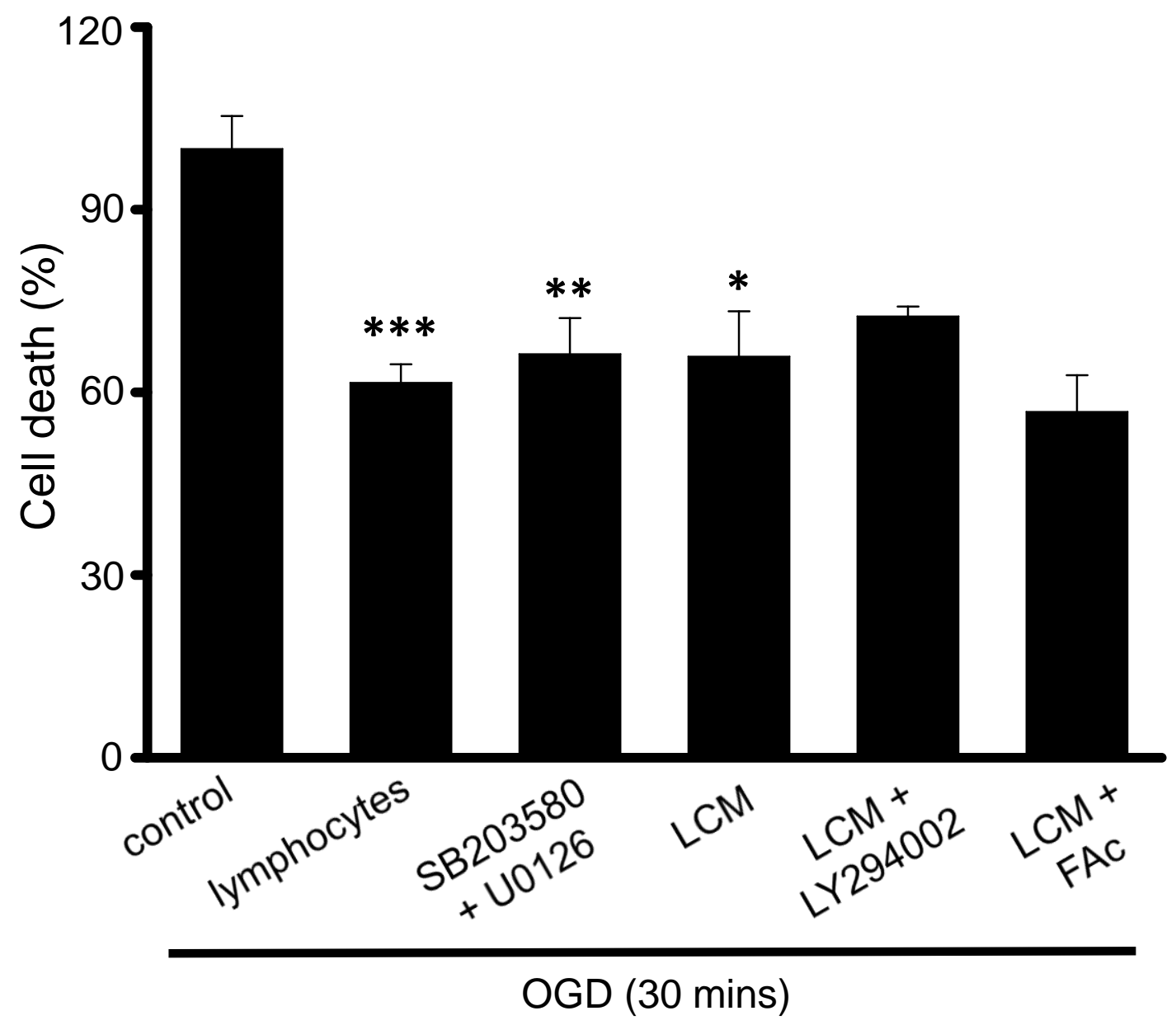

